\title{
A novel decision model based on mixed chase and level strategy for aggregate production planning under uncertainty: case study in beverage industry
}

DOI:

10.1016/j.cie.2017.09.044

\section{Document Version}

Accepted author manuscript

Link to publication record in Manchester Research Explorer

Citation for published version (APA):

Jamalnia, A., Yang, J-B., Xu, D., \& Feili, A. (2017). A novel decision model based on mixed chase and level strategy for aggregate production planning under uncertainty: case study in beverage industry. Computers and Industrial Engineering. https://doi.org/10.1016/j.cie.2017.09.044

Published in:

Computers and Industrial Engineering

\section{Citing this paper}

Please note that where the full-text provided on Manchester Research Explorer is the Author Accepted Manuscript or Proof version this may differ from the final Published version. If citing, it is advised that you check and use the publisher's definitive version.

\section{General rights}

Copyright and moral rights for the publications made accessible in the Research Explorer are retained by the authors and/or other copyright owners and it is a condition of accessing publications that users recognise and abide by the legal requirements associated with these rights.

\section{Takedown policy}

If you believe that this document breaches copyright please refer to the University of Manchester's Takedown Procedures [http://man.ac.uk/04Y6Bo] or contact uml.scholarlycommunications@manchester.ac.uk providing relevant details, so we can investigate your claim.

\section{OPEN ACCESS}




\section{Accepted Manuscript}

A novel decision model based on mixed chase and level strategy for aggregate production planning under uncertainty: case study in beverage industry

Aboozar Jamalnia, Jian-Bo Yang, Dong-Ling Xu, Ardalan Feili

PII: S0360-8352(17)30462-X

DOI: https://doi.org/10.1016/j.cie.2017.09.044

Reference:

CAIE 4930

To appear in:

Computers \& Industrial Engineering

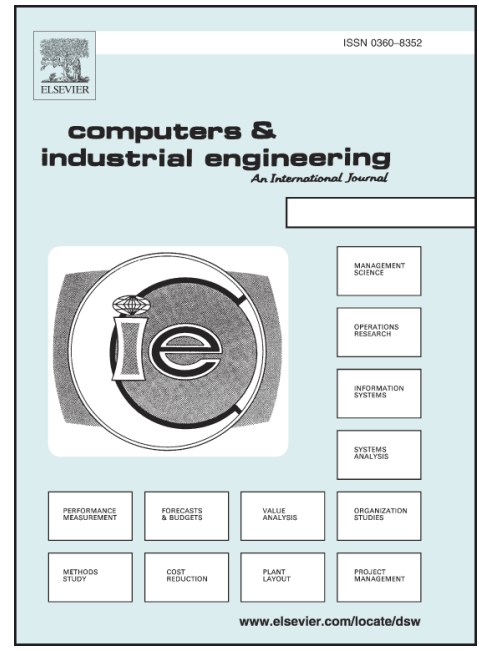

Received Date: 7 May 2017

Revised Date: $\quad 28$ August 2017

Accepted Date: $\quad 27$ September 2017

Please cite this article as: Jamalnia, A., Yang, J-B., Xu, D-L., Feili, A., A novel decision model based on mixed chase and level strategy for aggregate production planning under uncertainty: case study in beverage industry, Computers \& Industrial Engineering (2017), doi: https://doi.org/10.1016/j.cie.2017.09.044

This is a PDF file of an unedited manuscript that has been accepted for publication. As a service to our customers we are providing this early version of the manuscript. The manuscript will undergo copyediting, typesetting, and review of the resulting proof before it is published in its final form. Please note that during the production process errors may be discovered which could affect the content, and all legal disclaimers that apply to the journal pertain. 


\title{
A novel decision model based on mixed chase and level strategy for aggregate
} production planning under uncertainty: case study in beverage industry

\author{
Aboozar Jamalnia ${ }^{a}$, Jian-Bo Yang ${ }^{a}$, Dong-Ling $\mathrm{Xu}^{\mathrm{a}}$, Ardalan Feili ${ }^{\mathrm{b}}$ \\ ${ }^{a}$ Decision and Cognitive Sciences Research Centre, Alliance Manchester Business School, The \\ University of Manchester, Manchester, UK. \\ ${ }^{b}$ School of Management, Ferdowsi University of Mashhad, Mashhad, Iran. \\ "Corresponding author. Tel.: +447574318678. \\ Email addresses: aboozar.jamalnia@gmail.com (A. Jamalnia), \\ ¡ian-bo.yang@manchester.ac.uk (J.B. Yang), Ling.Xu@manchester.ac.uk (D.L. Xu), \\ Ardalan.feili@mail.um.ac.ir (A. Feili).
}

\section{A novel decision model based on mixed chase and level strategy for aggregate production planning under uncertainty: case study in beverage industry}

\begin{abstract}
The present study proposes a novel decision model to aggregate production planning (APP) decision making problem based on mixed chase and level strategy under uncertainty where the market demand acts as the main source of uncertainty. By taking into account the novel features, the constructed model turns out to be stochastic, nonlinear, multi-stage and multiobjective. APP in practice entails multiple-objectivity. Therefore, the model involves multiple objectives such as total revenue, total production costs, total labour productivity costs, optimum utilisation of production resources and capacity and customer satisfaction, and is validated on the basis of real world data from beverage manufacturing industry. Applying the recourse approach in stochastic programming leads to empty feasible space, and therefore the wait and see approach is used instead. After solving the model using the real-world industrial data, sensitivity analysis and several forms of trade-off analysis are conducted by changing different parameters/coefficients of the constructed model, and by analysing the compromise between objectives respectively. Finally, possible future research directions, with regard to the limitations of current study, are discussed.
\end{abstract}

Keywords: Aggregate production planning (APP); Uncertainty; Stochastic nonlinear multi-objective optimisation. 


\section{Introduction}

\subsection{General overview}

Aggregate production planning (APP) is a medium term production and employment planning that typically covers a time horizon which ranges from 3 to 18 months, and is concerned with determining optimal production volumes, hiring and lay off rates, workforce and inventory levels, backordering and subcontracting quantities, and so on with respect to the limitations of production resources for each time period within the planning horizon. This planning technique usually involves one product or a family of similar products, i.e. with similarities in production process, skills required, raw materials needed, etc. despite small differences so that considering the problem from an aggregated viewpoint is still credible.

In the hierarchy of production planning, APP falls between long-term strategic planning decisions such as new product development and short term production scheduling activities.

Similar to other production planning family members, APP also involves several objectives/criteria in practical settings. Due to the dynamic nature of APP and instable state of real world industrial environments, deterministic models for APP would lead to un-robust decisions. This implies that uncertainties need to be incorporated into the APP decision models.

Current study proposes a novel decision making model to APP which takes into account stochasticity, nonlinearity and multiple objectivity simultaneously. After considering new aspects in the proposed model, it becomes stochastic, nonlinear, multi-stage and multi-objective, and includes objectives such as total revenue, total production costs, total labour productivity costs, total costs of the changes in workforce level and customer satisfaction subject to bounds on inventory, backorder, subcontracting, workforce level, and so forth under uncertainty. The proposed approach models APP problem under the primary mixed strategy which integrates chase and level strategies to provide a holistic view of the APP.

The WWW-NIMBUS software (Miettinen and Mäkelä, 2006) will be used to solve the constructed stochastic, nonlinear, non-smooth, nonconvex, non-differentiable multi-objective optimisation model for the APP problem.

The paper is further organised as follows. The regular APP strategies are explained in the next subsection, and then problem under study is described in subsection 1.3. The relevant literature is reviewed in Section 2. The proposed APP model is presented in Section 3 with comprehensive details. The constructed model is implemented by utilising real world industrial data in Section 4 . 
Further experiments with the model are performed by trade-off analysis and sensitivity analysis in Section 5. Conclusion is drawn, and recommendations on possible future research directions are provided in Section 6.

\subsection{Fundamental APP strategies}

Three basic operations strategies can be used in APP, along with many combinations in between, to meet the fluctuating demand over time. One basic strategy is to level the workforce; the other is to chase demand with the workforce. With a perfectly level strategy, the rate of regular time output will be constant. Any variations in demand must then be absorbed using inventories, overtime, temporary workers, subcontracting, backorders or any of the demand-influencing options. With the pure chase strategy, the workforce level is changed to meet, or chase, demand. In this case, it is not necessary to carry inventory or to use any of the other variables available for APP; the workforce absorbs all the changes in demand (Reid and Sanders, 2002; Schroeder, 2003). The third strategy, the pure demand management strategy, is an approach that attempts to change or influence demand to fit available capacity by employing options such as pricing, advertising and developing alternative products and services (Slack, Brandon-Jones, Johnston, 2013).

Normally, the pure demand management policy is always considered as part of the level strategy. The present research also regards the demand management policy as a subset of the level strategy. Each of the two pure plans is applied only where its advantages strongly outweigh its disadvantages. For many organisations, however, these pure approaches do not match their required combination of competitive and operational objectives. Most operations managers are required simultaneously to reduce costs and inventory, to minimise capital investment and yet to provide a responsive and costumer-oriented approach at all times. For this reason, most organisations choose to follow a mixture of the two approaches (Slack, Brandon-Jones, Johnston, 2013).

\subsection{Problem statement}

The operations/manufacturing data was collected from ZamZam Group as a major soft drink producing company in West Asia. The company used to be the former subsidiary of PepsiCo in Iran but then it changed its brand name to ZamZam, and was extended from one plant to seventeen plants throughout the country and abroad. Over one hundred products which range from beverages to beers and mineral waters are produced by ZamZam Group. 
Normally, the company is operating in two 8 hour shifts. The first shift basically ends at $4 \mathrm{pm}$ every day, and then the second shift begins which are respectively called regular shift and extra shift by the operations management department of the company. The shifts are considered separately because of costs differences, e.g. wage costs in extra shift are higher.

The subcontracting is usually produced by ZamZam Isfahan, another branch of the ZamZam Group in city of Isfahan, Iran. Backorders should be met by the next time period at the latest.

The product demand follows a seasonal pattern, i.e. in spring and summer demand rises, and in autumn and winter demand declines. The company hires and lays off the workers, mostly lower skilled workers, according to changes in demand level. The newly hired workers go through a short training process.

The production planners implement APP mainly by using linear programming and simulation methods alongside their experience.

The seasonality of the demand for drink products and co-production by the plants in ZamZam Group (which makes options such as subcontracting practically possible) renders the Company a suitable case study for present research.

The primary objective of the current research is to find the optimal values of the production in regular shift and extra shift, backorder, inventory, subcontracting, workforce hired and laid off in day shift and night shift, product prices, etc. over the planning horizon for the company under study in presence of uncertainty. To present a holistic view of APP, it is modelled based on mixed chase and level strategy to include all possible demand and capacity management options. To take into account the multi-objective nature of APP, a comprehensive set of seven objective functions which are derived from real world situations are also considered.

As already mentioned in subsection 1.1, the APP is done for a family of similar products. As such, this study considers carbonated soft drinks in $300 \mathrm{ml}$ bottles in three flavours cola, orange and lemonade as a family of products in order to conduct APP process. This multiproduct APP decision making problem covers a time horizon of 12 months which includes 4 time periods, i.e. 4 seasons to reflect the seasonal oscillations of the product demands.

The customer demand is supposed to be the main source of uncertainty, and is presented in terms of three demand level scenarios: high demand, average demand and low demand with associated probabilities which are abbreviated as $\mathrm{H}, \mathrm{A}$ and $\mathrm{L}$ respectively throughout the study.

The forecasted demand acts as the driving force of the APP system. Seasonal demand patterns and unpredictability inherent in quantity and timing of received orders makes the whole APP system 
uncertain which in turn recommends utilising a decision modelling tool that takes account of these uncertainties.

Based on our discussion with marketing and sales managers of the company, we found out that when demand grows or declines, it will normally endure for several consecutive time periods while maintaining the seasonality pattern. Therefore, in this study, we assumed that the demand volume scenarios will be the same in all consecutive time periods in planning horizon.

\section{Background}

\subsection{Literature review}

The methodologies applied in the literature to deal with APP under uncertainty can be classified into six main categories: stochastic mathematical programming, possibilistic programming, fuzzy mathematical programming, simulation modelling, metaheuristics, and evidential reasoning. In present study, the most relevant category, i.e. the existing research on stochastic mathematical programming to APP which in turn comprises sub-categories such as stochastic linear programming, stochastic nonlinear programming, stochastic multi-objective optimisation and robust optimisation models of APP is concisely reviewed in following subsections.

\subsubsection{Stochastic multi-objective optimisation}

Rakes et al. (1984), Chen and Liao (2003) and Nowak (2013) utilised stochastic multi-objective optimisation techniques to consider APP under uncertainty.

Chen and Liao (2003) adopted a multi-attribute decision making approach to select the most efficient APP strategy such that selling price, market demand, cost coefficients, etc. are assumed to be stochastic variables. Nowak (2013) presented a procedure which combines linear multi-objective programming, simulation and an interactive approach with uncertain demand.

\subsubsection{Stochastic nonlinear programming}

Various types of stochastic nonlinear programming models for APP subject to uncertainty were developed by Vörös (1999), Ning et al. (2013), Mirzapour Al-e-hesham et al. (2013) and Lieckens and Vandaele (2014).

Ning et al. (2013) presented a multi-product, nonlinear APP model by applying uncertainty theory where the market demand, production cost, and so on are characterised as uncertain variables. 
Mirzapour Al-e-hesham et al. (2013) and Lieckens and Vandaele (2014) both suggested nonlinear, mixed integer programming methodologies to study APP decision problem in presence of uncertainty. Mirzapour Al-e-hesham et al. (2013) considered a multi-site APP problem in green supply chain with uncertain demand. Lieckens and Vandaele (2014) developed a multi-product, multi routing model where a routing consists of a sequence of operations on different resources. The uncertainty is associated with the stochastic nature of the both demand patterns and production lead times.

\subsubsection{Stochastic linear programming}

The research on stochastic linear programming to APP subject to uncertainty includes the studies carried out by Lockett and Muhlemann (1978), Kleindorfer and Kunreuther (1978), Günther (1982), Thompson et al. (1993) and Leung et al. (2006).

Thompson et al. (1993) developed linear programming frameworks to evaluate several APP policies where customer demand, most of the coefficients of the linear programming model and some parameters were presented with probability distributions to reflect the uncertainty in APP environment. A stochastic linear programming method to handle APP with stochastic demand and stochastic cost parameters was proposed by Leung et al. (2006).

\subsubsection{Robust optimisation}

Different kinds of robust optimisation techniques were employed by Leung and Wu (2004), Kanyalkar and Adil (2010), Mirzapour Al-e-hashem, Malekly and Aryanezhad (2011), Mirzapour Al-ehashem, Aryanezhad and Sadjadi (2012), Niknamfar, Akhavan Niaki and Pasandideh (2015), Modarres and Izadpanahi (2016), Entezaminia, Heidari and Rahmani (2016) and Makui et al. (2016) to study APP under uncertainty.

Modarres and Izadpanahi (2016) proposed a linear multi-objective optimisation model to APP with uncertain product demand which tries to minimise operational costs, energy costs and carbon emission. To deal with uncertain input data, a robust optimisation approach is also applied. 
Entezaminia, Heidari and Rahmani (2016) suggested a robust optimisation approach to handle a multi-site APP problem in green supply chain with regard to potential collection and cycling centres under uncertainty where customer demand and cost parameters are supposed to be of uncertain nature. Makui et al. (2016) implemented APP for products with very limited expiration dates. A robust optimisation method is also used due to inherent uncertainty of parameters of the constructed APP model.

\subsection{Novel features of the proposed APP model}

There are main features that distinguish the proposed decision making model in present study from the existing analytical models for APP in the literature, notably:

- Despite the popularity of various chase strategies of aggregate planning among operations managers (Buxey, 1995, 2003, 2005), the options included in these strategies such as the frequent hiring and lay-offs, working overtime and multiple shift operations are always major causes of productivity losses. Some literature treats the hiring process as a source of productivity loss. It is generally accepted that new workers need a certain period to adapt and to reach the same productivity as experienced workers. It is well known that lay-offs affect labour productivity not only in the short term, but also over longer horizons. Even seasonal fluctuations in employment can have an impact on productivity (Piper and Vachon, 2001). Hayes and Clark (1985) demonstrated that frequent lay-offs are associated with instability and confusion, which in turn have a negative impact on labour productivity. Frequent lay-offs and rehiring contributes to the depreciation of knowledge ( $\mathrm{Li}$ and Rajagopalan, 1998) and increase the likelihood of forgetting prior learning when rehiring (Kher et al., 1999). Lay-offs can also have a negative effect on the workforce's morale (Thomas and McClain, 1993) and affect the motivation level of the employees, which has also been proven to impact negatively on productivity (Huselin, 1998).

For the first time, the proposed APP decision making model in current research takes into account the productivity declines associated with chase policies of APP due to I) the frequent hiring and, thus the time required to learn the necessary skills and reach the same productivity as experienced labour, and II) workers' motivation decline as a result of frequent lay-offs. 
- In their previous research, the authors modelled demand management strategy of APP for the first time through a system dynamics simulation technique by considering the pricing and advertising options (see Jamalnia and Feili, 2013). Current study improves the previous study's demand management strategy framework fundamentally to take into account the stochastic nature of APP problem. Therefore, this is the first study of its kind that systematically considers the demand management policy in a mathematical programming model developed for APP by utilising pricing and advertising alternatives, which act based on precise mechanisms, that will be detailed in subsequent sections.

- In the hierarchy of production planning activities, capacity planning, as a long-range decision, is regarded as input to APP as a medium-range decision. The existing APP literature usually ignores the production capacity decisions or at best assumes the production capacity as a subjectively estimated fixed amount. Since the workforce level, as a major factor in determining the production capacity, oscillates constantly because of regular hiring and firing, supposing the production capacity for each product as a fixed value could lead to inaccurate decisions. Perhaps, an effective way in assigning the production capacity for each product would be determining the long-term/strategic capacity decisions in interaction with the medium-term APP decisions. In the proposed multi-stage, stochastic mathematical programming model of APP, the production capacities for different products are regarded as the first stage decision variables, i.e. deterministic decision variables that their values need to be determined dynamically in interaction with the stochastic part of the model at the beginning of planning horizon, and before the uncertainty is revealed.

Furthermore, a novel rational objective function is developed to minimise unutilised available production resources and manufacturing capacities.

- APP in practice involves stochasticity, nonlinearity and multi-objectivity. Stochasticity may arise from uncertainty present in constants/parameters of APP models such as demand, cost coefficients and product price. In addition to the constants/parameters, decision variables in APP models also can be of stochastic nature. Several factors from quadratic cost functions and stepwise product price function (if product price is no longer supposed to be a constant) to taking into account the learning curve effect can make the APP decision models nonlinear. The need for taking into account the multiple criteria associated with APP in real world, e.g. total revenue, total production costs, customer services, and so on and the need for trade- 
off analysis between these objectives necessitates multi-objective optimisation. The existing APP literature includes one or two of these features for the sake of simplicity.

This study represents the first APP model that deals with these three attribute all together under the same framework.

In present research, since the demand volume is hardly predictable, it makes the demand uncertain, and thus a stochastic variable. Mathematical operations related to embedding the demand management mechanism in the developed model via pricing and advertising policies which have been shown in equations (12)-(17), taking into account the labour productivity costs through constraints (22)-(31) and objective function (3), and several novel features cause the nonlinearity of the proposed model that have been detailed in relevant sections. Multiple objectivity of the proposed model better reflects the multi-objective nature of APP, and facilitates the trade-off analysis between the objectives.

In addition, the extensive set of objectives/criteria, i.e. 7 objective functions that has been presented in current study instead of simplification gives a comprehensive picture of APP.

Table 1 compares the main characteristics of the proposed APP model in current study to the existing stochastic mathematical programming models of APP.

Table 1: Comparison between existing stochastic mathematical programming models of APP

\begin{tabular}{|c|c|c|c|c|c|c|c|}
\hline \multirow{2}{*}{ Factor } & \multirow{2}{*}{$\begin{array}{c}\text { Stochastic } \\
\text { nonlinear multi- } \\
\text { objective } \\
\text { optimisation } \\
\begin{array}{c}\text { The present } \\
\text { study }\end{array}\end{array}$} & \multicolumn{2}{|c|}{$\begin{array}{c}\text { Stochastic linear multi-objective } \\
\text { optimisation }\end{array}$} & \multicolumn{2}{|c|}{ Stochastic nonlinear programming } & \multicolumn{2}{|c|}{ Stochastic linear programming } \\
\hline & & $\begin{array}{l}\text { Chen and Liao } \\
\qquad(2003)\end{array}$ & Nowak (2013) & $\begin{array}{c}\text { Mirzapour Al-e- } \\
\text { hesham et al. } \\
(2013)\end{array}$ & $\begin{array}{l}\text { Ning et al. } \\
\text { (2013) }\end{array}$ & $\begin{array}{l}\text { Leung et al. } \\
\qquad(2006)\end{array}$ & $\begin{array}{l}\text { Thompson et al. } \\
\text { (1993) }\end{array}$ \\
\hline Source of uncertainty & Product demand & $\begin{array}{l}\text { Selling price, } \\
\text { market } \\
\text { demand, cost } \\
\text { coefficients, } \\
\text { etc. }\end{array}$ & Product demand & $\begin{array}{l}\text { Product } \\
\text { demand }\end{array}$ & $\begin{array}{c}\text { Market } \\
\text { demand, } \\
\text { production } \\
\text { cost, and so on }\end{array}$ & $\begin{array}{l}\text { Cost } \\
\text { parameters, } \\
\text { product } \\
\text { demand, etc. }\end{array}$ & $\begin{array}{c}\text { Customer } \\
\text { demand } \\
\text { and coefficients/ } \\
\text { parameters }\end{array}$ \\
\hline $\begin{array}{c}\text { Primary APP strategy } \\
\text { considered }\end{array}$ & $\begin{array}{l}\text { Mixed chase and } \\
\text { level strategy }\end{array}$ & $\begin{array}{l}\text { Chase strategy, } \\
\text { level strategy } \\
\text { and mixed } \\
\text { chase and level } \\
\text { strategy }\end{array}$ & $\begin{array}{l}\text { Mixed chase and } \\
\text { level strategy }\end{array}$ & $\begin{array}{c}\text { Mixed chase } \\
\text { and level } \\
\text { strategy }\end{array}$ & $\begin{array}{c}\text { Mixed chase } \\
\text { and level } \\
\text { strategy }\end{array}$ & $\begin{array}{l}\text { Mixed chase } \\
\text { and level } \\
\text { strategy }\end{array}$ & $\begin{array}{l}\text { Chase strategy, } \\
\text { level strategy and } \\
\text { mixed chase and } \\
\text { level strategy }\end{array}$ \\
\hline $\begin{array}{l}\text { Demand management } \\
\text { policy }\end{array}$ & Considered & Not considered & Not considered & Not considered & Not considered & Not considered & Not considered \\
\hline Pricing option & Considered & Not considered & Not considered & Not considered & Not considered & Not considered & Not considered \\
\hline Advertising option & Considered & Not considered & Not considered & Not considered & Not considered & Not considered & Not considered \\
\hline Productivity measures & Considered & Not considered & Not considered & Not considered & Not considered & Not considered & Not considered \\
\hline Capacity decisions & Considered & Not considered & Not considered & Not considered & Not considered & Not considered & Not considered \\
\hline
\end{tabular}




\begin{tabular}{|c|c|c|c|c|c|c|c|}
\hline $\begin{array}{c}\text { Production resources } \\
\text { and capacity } \\
\text { utilisation }\end{array}$ & Considered & Considered & Not considered & Not considered & Not considered & Not considered & Not considered \\
\hline Learning effect & Considered & Not considered & Not considered & Not considered & Not considered & Not considered & Not considered \\
\hline Customer services & Considered & Considered & Not considered & Not considered & Not considered & Not considered & Not considered \\
\hline
\end{tabular}

Now, we link the new features detailed above to the performance of the proposed model compared to existing APP models in the literature. Considering an objective function and relevant constraints in the model to measure the productivity losses due to frequent hiring and lay off, gives the operations managers a gauge to assess the negative impacts of not having smooth workforce level on workers' morale and consequently on their motivation and productivity.

Instead of assuming the product demands as fixed values, which is totally inconsistent with real world situations, the proposed mechanism in this study gives the aggregate planners the flexibility to adjust demand dynamically via adjusting product prices and advertising costs in order to match demand with existing capacity.

Rather than supposing the production capacity for each product as a subjectively determined fixed quantity, which is unrealistic because of frequent hiring and lay off and oscillations in demand level, the proposed APP model provides enough flexibility for production planners to dynamically adjust the production capacity for different products when the uncertainty is revealed.

Present model provides a comprehensive picture of APP by considering stochasticity, nonlinearity and multi-objectivity simultaneously instead of simplification, which is a better reflection of how APP is performed in practice in industrial environments.

\section{Model development}

\subsection{Stochastic nonlinear multi-objective optimisation model of APP under uncertainty for the mixed chase and level strategy}

\subsubsection{Notations}

\subsubsection{Decision variables}

In notations definition for decision variables the subscripts $r, e, n, s$ and superscript $t$ stand for regular shift, extra shift, product $n$, scenario $s$ and time period $t$ respectively. $D, Q, B, I, H$ and $L$ denote product demand (unadjusted demand), production volume, backorder, inventory, hiring and 
lay off respectively. $P R, A C, P T$ and $P C$ show product price, advertising costs, production time and production capacity respectively.

\subsubsection{Parameters/constants}

$C, F, W$ and $v$ represent cost, time required to produce the first unit of a product, workforce level and warehouse space respectively. $C P R, P P R, F P R, F A C, S P T, T P C, M U$ and $M C$ denote the coefficient in the equation for product price, the parameter in the equation for product price, fixed price, fixed advertising costs, standard production time, total production capacity, hours of machine usage per unit of a product and machine capacity respectively.

Similar subscripts are also used for parameters/constants except that $s$ in the cost coefficient of the decision variable which shows subcontracting stands for subcontracting not scenario $s$. In addition, $u$ as subscript of the product demand denotes unadjusted demand, and $w$ stands for workers in salary cost parameters. The lower cases of the notations which were introduced for decision variables are used in subscript of the constants/parameters to be representative of those variables correspondingly. Max in subscripts denote the maximum values of the constants/parameters.

$P$ with subscript $s$ shows the probability associated with scenario $s$, and $p$ in subscript of production costs denotes production.

$\sigma$ is the regulator parameter, and $a, b$ and $c$ are constant terms in relevant equations.

\subsubsection{Objectives}

Since the wait and see method of stochastic programming is applied in present research, the objective functions need to be optimised for each demand quantity scenario subject to the constraints related to that specific scenario. Then, the expected value for each objective will be calculated by multiplying the obtained values for each objective by the probabilities assigned to each scenario, and adding up the products together.

A comprehensive set of the most pertinent objectives/criteria to APP in industrial settings are taken into account.

\section{I) Maximise total revenue}

The total revenue is maximised by multiplying the sales quantity, which is the expression inside the parenthesis, by product prices. 
The total revenue is used instead of total profit since in computing the total profit amount the cost items have already been considered, and thus the resulting overlaps between different objectives would undermine the trade-offs.

$\operatorname{Max} Z_{1}^{S}=\sum_{n=1}^{N} \sum_{t=1}^{T}\left(I_{n s}^{t-1}+Q_{r n s}^{t}+Q_{\text {ens }}^{t}+S_{n s}^{t}-I_{n s}^{t}\right) P R_{n s}^{t}$

II) Minimise total production costs

Total production costs include three items: all production costs except worker salaries in regular shift and extra shift, worker salaries in regular shift and extra shift and subcontracting costs.

$$
\begin{aligned}
\operatorname{Min} Z_{2}^{s}=\sum_{n=1}^{N} & \sum_{t=1}^{T}\left(C_{p n}^{t}\left(Q_{r n s}^{t}+Q_{\text {ens }}^{t}\right)\right. \\
& +\sum_{n=1}^{N} \sum_{t=1}^{T}\left(Q_{r n s}^{t-1} P T_{r n s}^{t}+F_{r n}\left(\left|Q_{r n s}^{t}-Q_{r n s}^{t-1}\right|+\varepsilon\right)^{b_{r}} \max \left(\left(Q_{r n s}^{t}-Q_{r n s}^{t-1}\right), 0\right)\right. \\
& \left.-\max \left(\left(Q_{r n s}^{t-1}-Q_{r n s}^{t}\right), 0\right) P T_{r n s}^{t-1}\right) C_{r w n}^{t} \\
& +\sum_{n=1}^{N} \sum_{t=1}^{T}\left(Q_{\text {ens }}^{t-1} P T_{\text {ens }}^{t}+F_{\text {en }}\left(\left|Q_{\text {ens }}^{t}-Q_{\text {ens }}^{t-1}\right|+\varepsilon\right)^{b_{e}} \max \left(\left(Q_{\text {ens }}^{t}-Q_{\text {ens }}^{t-1}\right), 0\right)\right. \\
& \left.-\max \left(\left(Q_{\text {ens }}^{t-1}-Q_{\text {ens }}^{t}\right), 0\right) P T_{\text {ens }}^{t-1}\right) C_{\text {ewn }}^{t} \\
& +\sum_{n=1}^{N} \sum_{t=1}^{T} C_{\text {sn }}^{t} S_{n s}^{t}
\end{aligned}
$$

III) Minimise total labour productivity costs

This objective function tries to minimise the positive deviations from the standard production time for both existing workforce, due to frequent lay-offs, and therefore workers motivation decline, and newly hired labour force because of the learning time required to reach a normal productivity level equivalent to the productivity of experienced labour. 
$\operatorname{Min} \mathrm{Z}_{3}^{S}$

$=\sum_{n=1}^{N} \sum_{t=1}^{T}\left(\max \left(P T_{r n s}^{t}-S P T_{r n}, 0\right) Q_{r n s}^{t-1}\right) C_{r w n}^{t}+\left(\max \left(P T_{e n s}^{t}-S P T_{e n}, 0\right) Q_{e n s}^{t-1}\right) C_{\text {ewn }}^{t}$

$+\sum_{n=1}^{N} \sum_{t=1}^{T}\left(\max \left(F_{r n}\left(\left|Q_{r n s}^{t}-Q_{r n s}^{t-1}\right|+\varepsilon\right)^{b_{r}}-S P T_{r n}, 0\right) \max \left(Q_{r n s}^{t}-Q_{r n s}^{t-1}, 0\right)\right) C_{r w n}^{t}$

$+\sum_{n=1}^{N} \sum_{t=1}^{T}\left(\max \left(F_{\text {en }}\left(\left|Q_{\text {ens }}^{t}-Q_{\text {ens }}^{t-1}\right|+\varepsilon\right)^{b_{e}}\right.\right.$

$\left.-S P T_{e n}, 0\right) \max \left(Q_{e n s}^{t}\right.$

$\left.\left.-Q_{\text {ens }}^{t-1}, 0\right)\right) C_{\text {ewn }}^{t}$

IV) Minimise the changes in workforce level

Having a smoother workforce level so as to minimise the negative side effects of regular hiring and firing which were detailed in subsection 2.2 is pursued by objective function $Z_{4}^{S}$.

$\operatorname{Min} Z_{4}^{s}=\sum_{t=1}^{T}\left(C_{r h}^{t} H_{r s}^{t}+C_{r l}^{t} L_{r s}^{t}+C_{e h}^{t} H_{e s}^{t}+C_{e l}^{t} L_{e s}^{t}\right)$

V) Maximise customer satisfaction

The fifth objective seeks to maximise the customer satisfaction by keeping the ratio of backorders to forecasted demands as low as possible.

$\operatorname{Max} Z_{5}^{S}=\sum_{n=1}^{N} \sum_{t=1}^{T}\left(1-\frac{B_{n s}^{t}}{D_{n s}^{t}}\right) / N T$

VI) Minimise total inventory holding, backordering and advertising costs

$\operatorname{Min} Z_{6}^{S}=\sum_{n=1}^{N} \sum_{t=1}^{T}\left(C_{i n}^{t} I_{n s}^{t}+C_{b n}^{t} B_{n s}^{t}\right)+\sum_{n=1}^{N} \sum_{t=1}^{T} A C_{n s}^{t}$

VII) Minimise unutilised production resources and capacity

Maximum utilisation of the company's resources, i.e. less subcontracting and more production in regular shift and extra shift is desired. 
$\operatorname{Min} Z_{7}^{S}=\sum_{n=1}^{N} \sum_{t=1}^{T}\left[\left(\frac{S_{n s}^{t}}{Q_{r n s}^{t}+Q_{e n s}^{t}}\right)+\left(1-\frac{Q_{r n s}^{t}}{P C_{r n}^{t}}\right)+\left(1-\frac{Q_{e n s}^{t}}{P C_{e n}^{t}}\right)\right] / 3 N T$

The expected value for objective $k, E\left(Z_{k}\right)$, is then obtained as follows:

$E\left(Z_{k}\right)=\sum_{s=1}^{S} P_{s} Z_{k}^{S}$

Where, $S$ is the total number of scenarios.

There is conflict between objective sets $\left(Z_{1}, Z_{7}\right)$ and $\left(Z_{2}, Z_{5}, Z_{6}\right)$ so that when production volume increases the total revenue increases, and unutilised production resources and capacity decreases but at the same time total production costs and total inventory holding, backordering and advertising costs, which are of minimisation type, increase in general, and vice versa. Increase/decrease in production quantity generally causes corresponding decline/rise in customer satisfaction, or $Z_{5}$, because of the rise in backorder volume. There is agreement within objective sets $\left(Z_{1}, Z_{7}\right),\left(Z_{3}, Z_{4}\right)$ and $\left(Z_{2}, Z_{5}, Z_{6}\right)$. That is, they improve or deteriorate together.

\subsubsection{Constraints}

Objective functions need to be optimised with respect to a set of constraints on capacity, advertising costs, price, subcontracting, inventory, and so on.

I) Capacity constraints

Production capacities allocated to each category of the products are regarded as first stage decision variables, i.e. decisions that need to be made before the uncertain outcomes are revealed.

Constraints (9) and (10) prevent the production quantity for each product in both regular shift and extra shift from going beyond their corresponding allocated capacities in each time period. As can be seen from constraint (11), the accumulation of the assigned production capacities to every single product in each time period should not violate the upper bound, or total production capacity.

$Q_{r n s}^{t} \leq P C_{r n}^{t}$

$\forall n, \forall t, \forall s$

$Q_{e n s}^{t} \leq P C_{e n}^{t}$

$\forall n, \forall t, \forall s \quad(10)$ 
$\sum_{n=1}^{N} \sum_{t=1}^{T}\left(P C_{r n}^{t}+P C_{e n}^{t}\right) \leq T P C$

II) Constraints for the demand management options

As it was already mentioned in subsection 1.2, the common demand management options are pricing, advertising, backordering and introducing complementary products. Since launching new products requires establishing new production facilities/production lines, only the first three options are considered in present study.

By applying pricing and advertising policies, business managers can shift the demand from peak periods to off-peak periods. The mechanism through which these policies are implemented will be explained in the current section by introducing relevant constraints.

In equality constraint (12), when the low and average demand scenarios are regarded, if the backorder quantity for a product in previous time period surpasses the threshold backorder quantity $B_{n \delta}^{t-1}$, then the coefficient of the fixed price $F P R_{n S}^{t}$ becomes 1 , and the coefficient of the expression $\left(C P R_{n} B_{n s}^{t-1}+P P R_{n}\right)$ equals zero. This means that even though the volume of the backorder/unsatisfied demand is high, but regarding the low or average quantity of the demand, the company should normally be able to meet the demand plus backorder. Therefore, the company under study should stick to a fixed price alternative rather than increasing the price through a higher backorder volume in price equation, equation 12 , to finally decrease the demand. Note that the backordered orders must be met by the next time period.

After consulting the operations managers of the company, the threshold backorder quantity of each product was intuitively determined as $55-60$ percent of the maximum backorder allowed for that product in a given time period.

On the other side, in equation (12), again in case that the low and average demand scenarios are considered, if the backorder amount in previous time period is less than the backorder threshold level, the coefficient of the fixed price $F P R_{n s}^{t}$ switches to 0 , and the coefficient of the term $\left(C P R_{n} B_{n s}^{t-1}+P P R_{n}\right)$ becomes 1 , which means the firm under study is going to follow the price regulation alternative, i.e. to reduce the price as a result of decrease in backorder quantity in previous planning period in the equation $P R_{n s}^{t}=\left(C P R_{n} B_{n s}^{t-1}+P P R_{n}\right)$ to finally cause a rise in demand. 
As an explanation, the linear equation of the product prices in terms of the backorders was provided using the linear regression method to estimate the parameters of the equation.

A very similar mechanism is applied in equation (13), for the high demand scenario condition, to implement price regulation, and in equations (14) and (15) in order to execute the advertisement policy.

For example, in equation (14), in condition of low and average demand scenarios for a product, if the backlogged order quantity for a product in previous time period falls below its predetermined backorder threshold limit $B_{n \delta}^{t-1}$, the company managers will decide to increase advertising costs via relatively lower backorder quantity in advertising costs equation $A C_{n s}^{t}=\left(a_{A C_{n}}+\frac{b_{A C_{n}}}{\sigma_{A C_{n}} B_{n s}^{t-1}+c_{A C_{n}}}\right)$, since its coefficient equals 1 , and the coefficient of $F A C_{n s}^{t}$, fixed advertising costs, turns out to be 0 . This will in turn lead to an increase in demand.

The opposite occurs when the previous time period backordered order amount goes beyond the threshold level.

The special features of the hyperbolic function $A C_{n s}^{t}=\left(a_{A C_{n}}+\frac{b_{A C_{n}}}{\sigma_{A C_{n} B_{n s}^{t-1}+c_{A C_{n}}}}\right)$ make it ideal to represent the relationship between advertising costs and backorder quantity in practice, i.e. when backorder level increases, the advertisement costs do not fall to zero with a fixed slope but tends to the constant $a_{A C_{n}}$ with a decreasing slope, and when backorder level decreases, the advertising costs do not tend to infinity but approaches $\left(a_{A C_{n}}+\frac{b_{A C_{n}}}{c_{A C_{n}}}\right)$ with a rising slope. The regulator parameter $\sigma_{A C_{n}}$, which assumes values between zero and one, and is determined intuitively, helps prevent out of control changes in advertising costs in terms of backorder level.

At one point, when $B_{n s}^{t-1}-B_{n \delta}^{t-1}=0$, equations (12)-(15) shut down, since both sides of the equations become 0 . However, as the variables are supposed to be continuous in general, the likelihood that this will be the case is absolutely narrow, and the formulas work out for the amounts of backlogged orders which are very close to the threshold backorder level, i.e. $B_{n \delta}^{t-1} \pm \varepsilon$ where $\varepsilon$ is assumed to be a very small positive number.

Note that both $F P R_{n s}^{t}$ and $F A C_{n s}^{t}$ are calculated by plugging $B_{n \delta}^{t-1}$ into $P R_{n s}^{t}=\left(C P R_{n} B_{n s}^{t-1}+\right.$ $\left.P P R_{n}\right)$ and $A C_{n s}^{t}=\left(a_{A C_{n}}+\frac{b_{A C_{n}}}{\sigma_{A C_{n}} B_{n s}^{t-1}+c_{A C_{n}}}\right)$ respectively.

In practice, demand for each product would have opposite relationship with that product price and direct relationship with incurred advertising costs of the product, which is embedded in equations (16) and (17). As such, it can be seen from equation (16) that under low/average demand 
circumstances, if backorder level in previous planning period falls below the threshold level, advertising costs will increase, and product price will drop compared to that of threshold limit, which in turn will make the expression $\max \left(\frac{\frac{A C_{n s}^{t}}{P R_{n s}^{t}-\frac{A C_{n}^{t}}{P R_{n_{\delta}}^{t}}}}{\frac{A C_{n_{\delta}}^{t}}{P R_{n_{\delta}}^{t}}}, 0\right)$, that indicates the amount of growth or decline in demand, a positive value. Consequently, the adjusted/managed demand will grow accordingly. $A C_{n_{\delta}}^{t}$ and $P R_{n \delta}^{t}$ represent the advertisement costs and product price in terms of threshold backorder level. The regulator parameter in this equation, $\sigma_{D_{n L A}}$, which takes on values in the interval $[0,1]$, is determined intuitively, and its role is to prevent rampant increase or decrease in the adjusted demand quantity.

In situations that backorder volume surpasses the specified threshold limit, no change will occur in unadjusted demand.

A quite similar justification could be provided for the high demand condition in equation (17).

$$
\begin{aligned}
\left(B_{n s}^{t-1}-B_{n \delta}^{t-1}\right) & P R_{n s}^{t} \\
& =\left(\max \left(B_{n s}^{t-1}-B_{n \delta}^{t-1}, 0\right)\right) F P R_{n s}^{t}+\left(\min \left(B_{n s}^{t-1}-B_{n \delta}^{t-1}, 0\right)\right)\left(C P R_{n} B_{n s}^{t-1}\right. \\
& \left.+P P R_{n}\right) \quad \forall n, \forall t, \forall \mathrm{s} \in\{L, A\}
\end{aligned}
$$

$$
\begin{aligned}
& \left(B_{n s}^{t-1}-B_{n \delta}^{t-1}\right) P R_{n H}^{t} \\
& =\left(\min \left(B_{n s}^{t-1}-B_{n \delta}^{t-1}\right)\right) F P R_{n s}^{t}+\left(\max \left(B_{n s}^{t-1}-B_{n \delta}^{t-1}\right)\right)\left(C P R_{n} B_{n s}^{t-1}\right. \\
& \left.+P P R_{n}\right) \\
& \left(B_{n s}^{t-1}-B_{n \delta}^{t-1}\right) A C_{n s}^{t} \\
& =\left(\max \left(B_{n s}^{t-1}-B_{n \delta}^{t-1}\right)\right) F A C_{n s}^{t} \\
& +\left(\min \left(B_{n s}^{t-1}-B_{n \delta}^{t-1}\right)\right)\left(a_{A C_{n}}+\frac{b_{A C_{n}}}{\sigma_{A C_{n}} B_{n s}^{t-1}+c_{A C_{n}}}\right) \quad \forall n, \forall t, \forall s \in\{L, A\} \\
& \left(B_{n s}^{t-1}-B_{n \delta}^{t-1}\right) A C_{n H}^{t} \\
& =\left(\min \left(B_{n s}^{t-1}-B_{n \delta}^{t-1}\right)\right) F A C_{n s}^{t} \\
& +\left(\max \left(B_{n s}^{t-1}-B_{n \delta}^{t-1}\right)\right)\left(a_{A C_{n}}+\frac{b_{A C_{n}}}{\sigma_{A C_{n}} B_{n s}^{t-1}+c_{A C_{n}}}\right)
\end{aligned}
$$


$D_{n s}^{t}=D_{\text {uns }}^{t}\left(1+\sigma_{D_{n L A}} \max \left(\frac{\frac{A C_{n s}^{t}}{P R_{n s}^{t}}-\frac{A C_{n_{\delta}}^{t}}{P R_{n_{\delta}}^{t}}}{\frac{A C_{n_{\delta}}^{t}}{P R_{n_{\delta}}^{t}}}, 0\right)\right)$

$D_{n H}^{t}=D_{u n H}^{t}\left(1+\sigma_{D_{n H}} \min \left(\frac{\frac{A C_{n H}^{t}}{P R_{n H}^{t}}-\frac{A C_{n_{\delta-1}}^{t}}{P R_{n_{\delta-1}}^{t}}}{\frac{A C_{n_{\delta-1}}^{t}}{P R_{n_{\delta-1}}^{t}}}, 0\right)\right)$

$A C_{n s}^{t} \leq A C_{n s \max }^{t}$

$\forall n, \forall t, \forall s$

III) Production and inventory balance

Equation (19) shows that if remaining inventory from previous time period plus production in both regular shift and extra shift and subcontracting exceed the sum of backorder from previous time period and forecasted demand in present time period, the inventory level would be positive; otherwise a portion of the received orders has to be backordered. Therefore, backorder and inventory cannot exist simultaneously for the same product in a given time period.

As is evident from equation (19), in case that the sum of inventory quantity from previous time period and capacity of regular shift production in current time period do not suffice the backorder from previous time period besides product demand in current time period, the subcontracting and extra shift production is allowed. Note that in model implementation process in Section 4 , the wage costs for production in regular shift are assumed to be lower than that of production in extra shift. Additionally, total production costs (including wage costs) for each unit of products in regular shift and extra shift are supposed to be significantly lower than subcontracting costs. These factors will also encourage producing as much as possible in regular shift before using extra shift and, producing as much as possible in regular shift and extra shift before turning toward subcontracting.

The very small quantity $\varepsilon$ in the denominator of the fraction which acts as the coefficient of the expression $\left(Q_{e n s}^{t}+S_{n s}^{t}\right)$ is to make sure that the opposite side is also possible by avoiding the undefined operation, i.e. zero divided by zero.

The equations (20) and (21) prevent backorders and subcontracting from exceeding their upper limits. 
$I_{n s}^{t-1}-B_{n s}^{t-1}+Q_{r n s}^{t}+\left(\frac{\max \left(D_{n s}^{t}+B_{n s}^{t-1}-P C_{r n}^{t}-I_{n s}^{t-1}, 0\right)}{\left(\max \left(D_{n s}^{t}+B_{n s}^{t-1}-P C_{r n}^{t}-I_{n s}^{t-1}, 0\right)+\varepsilon\right)}\right)\left(Q_{e n s}^{t}+S_{n s}^{t}\right)-D_{n s}^{t}$

$$
=I_{n s}^{t}-B_{n s}^{t}
$$

$\forall n, \forall t, \forall s$

$B_{n s}^{t} \leq B_{n s \max }^{t}$

$\forall n, \forall t, \forall s$

$S_{n s}^{t} \leq S_{n s \max }^{t}$

$\forall n, \forall t, \forall s \quad(21)$

\section{IV) Recruitment constraints}

Hiring, lay off and regulating the workforce level are central activities in APP process, which are modelled through precise and innovative mathematical equations/constraints in current study as follows.

The learning curve effect is considered in the constructed APP model to better reflect the worker experience factor in computing the required labour-hours. Simply stated, suppose $F$ is the time required to produce the first unit of a product, $Q$ is the cumulative quantity of production, and $b$ is the learning index which is calculated as natural logarithm (Ln) of learning curve percentage $\div \operatorname{Ln} 2$. The cumulative average production time per unit and total cumulative production time will be $F Q^{b}$ and $\left(F Q^{b}\right) Q$ respectively.

The company needs to hire new workers if the production quantity in present time period is going to increase compared to the production quantity in previous time period in both regular shift and extra shift, and lay off otherwise, which is indicated by equations (22)-(24) and (26)-(28). As newly hired labour needs more time to learn necessary skills, and reach the productivity equivalent to the productivity level of experienced workers, it would be quite normal to utilise the learning effect in computing the man-hours required to be employed.

An absolute value function is used in equations (22) and (26) to avoid computational errors due to negative bases with fractional exponents. The very small value $\varepsilon$ is added to $\left|Q_{r n s}^{t}-Q_{r n s}^{t-1}\right|$ to make sure that a computation error will not happen when the base is zero and power is decimal.

But, in making lay off decisions, the productivity of the existing experienced workforce, which is supposed to be mainly reflected through production time, is considered. Regular hiring and firing are regarded as fundamental alternatives for the chase strategies of APP. Frequent firing/lay off is expected to have an intense negative effect on the productivity of the existing workers due to declined motivation.

Among different mathematical functions, the logarithmic function would effectively represent changes in production time with regard to variations in the number of man-hours laid off. That is, 
given that all parameters in equation (25) are nonnegative, when there is no lay off, the production time of product $n$ would reduce to a constant, i.e. $a_{P T_{r n}}+\operatorname{Ln}\left(c_{P T_{r n}}\right)$, and when the lay off increases, the production time rises, not with fixed slope, but with decreasing slope.

Equations (26)-(29) which are related to recruitments, lay-offs and production times in extra shift can be described similarly.

Constraints (30) and (31) ensure that workforce levels in both regular shift and extra shift will not exceed the maximum allowable workforce level.

$$
\begin{aligned}
& H_{r s}^{t}=\sum_{n=1}^{N} F_{r n}\left(\left|Q_{r n s}^{t}-Q_{r n s}^{t-1}\right|+\varepsilon\right)^{b_{r}} \max \left(\left(Q_{r n s}^{t}-Q_{r n s}^{t-1}\right), 0\right) \\
& L_{r s}^{t}=\sum_{n=1}^{N} \max \left(\left(Q_{r n s}^{t-1}-Q_{r n s}^{t}\right), 0\right) P T_{r n s}^{t-1} \\
& L_{r n s}^{t}=\max \left(\left(Q_{r n s}^{t-1}-Q_{r n s}^{t}\right), 0\right) P T_{r n s}^{t-1} \\
& P T_{r n s}^{t}=a_{P T_{r n}}+\operatorname{Ln}\left(b_{P T_{r n}} L_{r n s}^{t}+c_{P T_{r n}}\right) \\
& H_{e s}^{t}=\sum_{n=1}^{N} F_{e n}\left(\left|Q_{e n s}^{t}-Q_{e n s}^{t-1}\right|+\varepsilon\right)^{b_{e}} \max \left(\left(Q_{\text {ens }}^{t}-Q_{\text {ens }}^{t-1}\right), 0\right) \\
& L_{\text {es }}^{t}=\sum_{n=1}^{N} \max \left(\left(Q_{\text {ens }}^{t-1}-Q_{\text {ens }}^{t}\right), 0\right) P T_{\text {ens }}^{t-1} \\
& L_{\text {ens }}^{t}=\max \left(\left(Q_{\text {ens }}^{t-1}-Q_{\text {ens }}^{t}\right), 0\right) P T_{\text {ens }}^{t-1} \\
& P T_{e n s}^{t}=a_{P T_{e n}}+\operatorname{Ln}\left(b_{P T_{e n}} L_{e n s}^{t}+c_{P T_{e n}}\right) \\
& \sum_{n=1}^{N} Q_{r n s}^{t-1} P T_{r n s}^{t}+H_{r s}^{t}-L_{r s}^{t} \leq W_{r s \max }^{t} \\
& \sum_{n=1}^{N} Q_{e n s}^{t-1} P T_{e n s}^{t}+H_{e s}^{t}-L_{e s}^{t} \leq W_{e s \max }^{t} \\
& \forall n, \forall t, \forall s \\
& \forall n, \forall t, \forall s
\end{aligned}
$$

V) Machine capacity and warehouse space 
Constraint (32) is to make sure that total machine usage in regular shift and extra shift will not violate the upper bound on machine capacity available.

The company should not store finished product inventory which is more than the quantity that the available warehouse space allows, which is guaranteed by constraint (33).

$$
\begin{aligned}
& \sum_{n=1}^{N} M U_{n}\left(Q_{r n s}^{t}+Q_{e n s}^{t}\right) \leq M C_{\text {max }}^{t} \\
& \sum_{n=1}^{N} v_{n} I_{n s}^{t} \leq V_{\text {max }}^{t} \\
& Q_{r n s}^{t}, Q_{e n s}^{t}, S_{n s}^{t}, B_{n s}^{t}, I_{n s}^{t}, P C_{r n}^{t}, P C_{e n}^{t}, P T_{r n s}^{t}, P T_{e n s}^{t}, H_{r s}^{t}, L_{r s}^{t}, L_{r n s}^{t}, H_{e s}^{t}, L_{e s}^{t}, L_{e n s}^{t}, D_{n s}^{t}, P R_{n s}^{t}, \\
& A C_{n s}^{t} \geq 0
\end{aligned}
$$

\section{Case study}

The constructed stochastic, nonlinear, nonconvex, non-differentiable, multi-stage, multi-objective optimisation model of APP under uncertainty is validated by implementing it in ZamZam Group, which was described in problem statement section, based on the following conditions:

- As already stated in subsection 1.3 , carbonated soft drinks in $300 \mathrm{ml}$ bottles in three flavours Cola, Orange and Lemonade are considered as a family of products in order to run APP process. The multiproduct APP decision making problem is conducted over a span of 12 months which includes 4 time periods, i.e. 4 seasons to reflect the seasonality of the forecasted demand.

- The unadjusted forecasted demand for each product under different scenarios, cost figures and other input data are presented in Table 2-Table 4 in Appendix.

- Maximum total capacity allocated to all products over the planning horizon $T$ is $138,670,042$ bottles.

- The initial inventories for products 1, 2 and 3 are 208,796, 102,698 and 38,113 bottles respectively.

- There is no initial backorder. 
- Previous time-period production in regular shift at the beginning of the planning horizon for products 1,2 and 3 is $10,278,331,2,944,435$ and 907,620 bottles respectively.

- Previous time-period production in extra shift at the beginning of the planning horizon for all products is zero.

- The time required to produce first unit of all products in the automated production line in all time periods by newly employed workers is 0.001088 man-hour/bottle in both regular shift and extra shift, and the standard production time for all products in both regular shift and extra shift is estimated as 0.00075 man-hour/bottle.

- The upper bound on workforce level in all time periods for both regular shift and extra shift is 17021 man-hour.

- The learning rate in both regular shift and extra shift is supposed to be 0.95 .

- $\left(C P R_{n}, P P R_{n}\right)$ for products 1,2 and 3 are computed through linear regression method by using past data as $(0.00000002028,0.0894),(0.00000004092,0.0897)$ and $(0.0000001287$, 0.0908) correspondingly.

- The approximation for $\left(a_{A C_{n}}, b_{A C_{n}}, c_{A C_{n}}\right)$, are respectively $(-37,749,178,519,000,000$, $2,513,079),(-21,987,56,251,340,000,1,459,053)$ and $(-6,469,5,122,434,000,427,396)$ for products 1,2 and 3 by applying curve fitting methods.

- The approximated values for $\left(a_{P T_{n}}, b_{P T_{n}}, c_{P T_{n}}\right)$ in both regular shift and extra shift for products 1,2 and 3 are (4.550524, 0.000000001442927, 0.01056907), (4.546664, $0.000000002897013,0.01060994)$ and $(4.564944,0.000000008527615,0.01041776)$ respectively by using curve fitting methods.

- The probability of low, average and high demand scenarios are estimated by marketing managers as $0.30,0.50$ and 0.20 respectively using the past demand data.

- $\sigma_{D_{n s}}$ and $\sigma_{A C_{n}}$ are intuitively determined as 0.20 and 1 respectively through a trial and error process by running the model several times with regard to different values of these parameters.

- All monetary values, e.g. costs, revenues, profits, etc. are supposed to be in British Pound (GBP).

The core model for the mixed chase and level strategy by exerting the recourse approach for the industrial case under study has 504 variables, over 1050 constraints and 7 objective functions. Besides the deficiencies of the recourse approach (which do not lie in present study's scope), this model has no feasible space mostly because of the presence of large number of highly inconsistent constraints related to different demand scenarios. 
As such, we resort to the wait and see approach as another stochastic programming methodology. By adopting the wait and see method, rather than putting all of the constraints related to different demand scenarios together and calculating the expected values in the objective functions, we will have a separated problem for each scenario. After getting the solutions of these problems, then the expected values for each objective function could be calculated regarding different scenarios.

Consequently, employing the wait and see approach creates three equal size problems with 184 variables, 205 constraints and 7 objectives, where each problem represents one of the three demand volume scenarios, i.e. low, average and high.

These nonlinear, multi-objective optimisation problems are non-smooth due to the presence of the $\mathrm{max} / \mathrm{min}$ operators, and non-differentiable because of the existence of absolute value functions and rational functions in the model. They are nonconvex as well, which diminishes the existing algorithms and software capabilities to deal with them efficiently. However, the WWW-NIMBUS software has the capability to run these kinds of problems.

During an interactive process, and by several classifications, the decision markers, i.e. operations managers, selected the most satisfactory solutions among the set of Pareto optimal solutions, which were presented in Table 5.

Table 5: The solutions for objectives

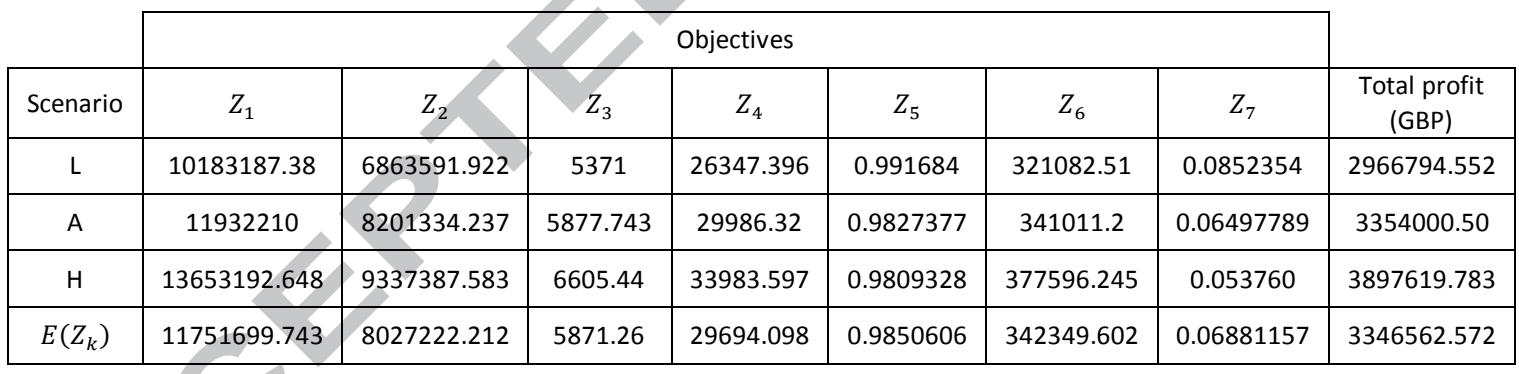

The Total profit column in Table 5 is simply calculated by deducting the cost items, $Z_{2}, Z_{3}, Z_{4}$ and $Z_{6}$, from the total revenue $Z_{1}$ for each scenario. Because of the relatively low quantity of backorder compared to demand volume for all products, the customer satisfaction level, $Z_{5}$, is quite high for all scenarios. Since most of the received orders are met by manufacturing in regular shift and extra shift instead of subcontracting, the unutilised production capacity and resources, $Z_{7}$, is significantly low, i.e. lower than $10 \%$ in all scenarios. Total production costs and total labour productivity costs have the highest and lowest amounts respectively among the cost items. The row $E\left(Z_{k}\right)$ is the expected value of each column. 
The detailed solutions of the model for decision variables with respect to the average demand scenario (the most likely scenario) have been provided in Table 6 .

As Table 6 indicates, since the backorder quantities of all products are lower than their threshold level, the adjusted demand shows some increase for all products. As already stated, demand follows a seasonal pattern, i.e. rises in spring and summer, time periods 1 and 2 respectively, and declines in autumn and winter, time periods 3 and 4 respectively. Consequently, production in both regular shift and extra shift, subcontracting, backordering, etc. depend on this seasonal demand pattern. As can be seen from Table 6, production time in regular shift and extra shift depend on lay off rate. That is, when lay off rate increases, production time also increases. Since we cannot have backorder and inventory simultaneously in a given time period, the values of these two decision variables are not positive at the same time within a specific time period. This is also true about hiring and lay off decision variables.

Table 6: The solutions for decision variables with regard to the average demand scenario

\begin{tabular}{|c|c|c|c|c|c|c|c|c|}
\hline Product & $\begin{array}{l}\text { Time } \\
\text { period }\end{array}$ & $Q_{r n s}^{t}$ & $Q_{e n s}^{t}$ & & $B_{n s}^{t}$ & $I_{n s}^{t}$ & $D_{n s}^{t}$ & $P R_{n s}^{t}$ \\
\hline \multirow{4}{*}{1} & 1 & 9764414 & 5128044 & 1352371 & 479112.5 & 0 & 18421850 & 0.0894 \\
\hline & 2 & 12251580 & 6893643 & 2250134 & 576873.3 & 0 & 22096150 & 0.10282 \\
\hline & 3 & 12182370 & 7025935 & 1991727 & 482023.3 & 0 & 23174030 & 0.09845751 \\
\hline & 4 & 10924350 & 2789918 & 0 & 0 & 1140000 & 12804550 & 0.1023844 \\
\hline \multirow{4}{*}{2} & 1 & 5357878 & 2267030 & 919523.6 & 184073 & 0 & 9341478 & 0.0897 \\
\hline & 2 & 6684127 & 3230183 & 1275832 & 283409.7 & 0 & 1172213 & 0.09778276 \\
\hline & 3 & 6091057 & 3800000 & 1140000 & 210937 & 0 & 11645070 & 0.1039598 \\
\hline & 4 & 5725491 & 1779934 & 0 & 0 & 665000 & 7160862 & 0.1010076 \\
\hline \multirow{4}{*}{3} & 1 & 1396332 & 828745.8 & 465668.2 & 71815.71 & 0 & 3005615 & 0.0908 \\
\hline & 2 & 1900000 & 1235567 & 373868.7 & 94471.8 & 0 & 3679927 & 0.001038213 \\
\hline & 3 & 1900000 & 1268123 & 209000.0 & 82680.4 & 0 & 3647129 & 0.1064573 \\
\hline & 4 & 1710000 & 550708.5 & 0 & 0 & 209000 & 2163666 & 0.1011092 \\
\hline
\end{tabular}

Table 6: (Continued)

\begin{tabular}{|c|c|c|c|c|c|c|c|c|}
\hline Product & $\begin{array}{c}\text { Time } \\
\text { period }\end{array}$ & $A C_{n s}^{t}$ & $P T_{r n s}^{t}$ & $P T_{\text {ens }}^{t}$ & $P C_{r n}^{t}$ & $P C_{\text {en }}^{t}$ & $L_{\text {rns }}^{t}$ & $L_{\text {ens }}^{t}$ \\
\hline \multirow{4}{*}{1} & 1 & 33287 & 0.0006834604 & 0.0006834248 & 10652830 & 5458388 & 0 & 0 \\
\cline { 2 - 9 } & 2 & 20343.33 & 0.0006855588 & 0.0006907746 & 1322335 & 7167241 & 0 & 0 \\
\cline { 2 - 9 } & 3 & 18489.73 & 0.0007021254 & 0.0007262385 & 12769130 & 7705931 & 53.44379 & 17.1281 \\
\cline { 2 - 9 } & 4 & 20286.31 & 0.0008620157 & 0.001121918 & 11300030 & 3042345 & 955.4841 & 3041.74 \\
\hline \multirow{3}{*}{2} & 1 & 16566 & 0.0006926231 & 0.0006900488 & 5479290 & 2407143 & 0 & 0 \\
\cline { 2 - 9 } & 2 & 11444.35 & 0.0006809573 & 0.0006930337 & 6718734 & 3397951 & 0 & 0 \\
\hline & 3 & 9520.577 & 0.0007783704 & 0.0007111014 & 6593796 & 4063849 & 424.8072 & 11.43078 \\
\hline & 4 & 10900.48 & 0.0007658467 & 0.001093747 & 6212692 & 1914078 & 319.7334 & 1432.979 \\
\hline
\end{tabular}




\begin{tabular}{|c|c|c|c|c|c|c|c|c|}
\hline \multirow{3}{*}{3} & 2 & 3529.191 & 0.0006857249 & 0.0006930484 & 2067080 & 1302997 & 0 & 0 \\
\cline { 2 - 10 } & 3 & 3091.244 & 0.0006997249 & 0.0007105958 & 1994969 & 1350177 & 4.824619 & 11.69443 \\
\cline { 2 - 10 } & 4 & 3314.106 & 0.0008168638 & 0.001037631 & 1719795 & 589705.5 & 143.0723 & 536.5157 \\
\hline
\end{tabular}

Table 6: (Continued)

\begin{tabular}{|c|c|c|c|c|}
\hline Time period & $H_{r S}^{t}$ & $H_{e s}^{t}$ & $L_{r s}^{t}$ & $L_{e s}^{t}$ \\
\hline 1 & 1160.107 & 2931.414 & 0 & 0 \\
\hline 2 & 1664.042 & 1243.059 & 0 & 0 \\
\hline 3 & 56.53672 & 318.0996 & 487.7772 & 25.245 \\
\hline 4 & 48.63386 & 27.94257 & 1443.121 & 5031.432 \\
\hline
\end{tabular}

\section{Further experiments with the model}

The sensitivity of the obtained solutions to the changes in objective functions and the parameters are examined via the following scenarios.

To avoid excessive elaboration, the following experiments are conducted based on the most probable scenario, i.e. the average demand scenario, as the outcomes for other demand scenarios would normally be similar.

\subsection{Scenario 1: construct pay-off table}

The APP model is run when only one objective is considered each time, and then the values of other objective functions are computed using the solutions obtained for decision variables. As such, the result would be a pay-off table which has been shown in Table 7.

Table 7: Pay-off table with regard to scenario 1

\begin{tabular}{|c|c|c|c|c|c|c|c|}
\cline { 2 - 8 } \multicolumn{1}{c|}{} & $Z_{1}$ & $Z_{2}$ & $Z_{3}$ & $Z_{4}$ & $Z_{5}$ & $Z_{6}$ & $Z_{7}$ \\
\hline Run 1 & $\mathbf{1 2 4 2 5 4 9 5 . 0 1}$ & 8384408.86 & 6046.43 & 29918.14 & 0.98370698 & 329513.45 & 0.0666278 \\
\hline Run 2 & 11418666.13 & $\mathbf{7 8 5 0 2 0 0 . 5 6 7}$ & 5377.46 & 29352.49 & 0.9830239 & 339814.18 & 0.0786851 \\
\hline Run 3 & 11344458.39 & 7877253.001 & $\mathbf{4 8 3 6 . 0 0 6}$ & 29400.36 & 0.9841467 & 316203.26 & 0.1191503 \\
\hline Run 4 & 11555656.12 & 8474569.806 & 6580.23 & $\mathbf{2 7 9 9 1 . 5 3}$ & 0.9840656 & 355382.44 & 0.1231655 \\
\hline Run 5 & 11454465.8 & 8323891.045 & 6338.770 & 2846.05 & $\mathbf{0 . 9 8 4 6 8 3 8}$ & 314496.49 & 0.1214955 \\
\hline Run 6 & 11308298.45 & 8699349.84 & 6347.672 & 29469.35 & 0.9845023 & $\mathbf{3 1 0 9 2 5 . 2 0}$ & 0.1224783 \\
\hline Run 7 & 11372436.24 & 8158420.857 & 6298.19 & 29195.34 & 0.9838712 & 333014.64 & $\mathbf{0 . 0 3 1 5 2 1 6}$ \\
\hline
\end{tabular}

The results are also shown in Fig. 1. Because the values of objectives range from numbers between zero and one to eight digit numbers, it would be hard to show them on the same figure simultaneously. Thus, the current values of objectives, i.e. their values with respect to the average demand scenario in Table 5 are assumed to be 1 (regardless of whether they are of minimisation or maximisation type), and the percentages of increase or decrease in their values regarding different 
runs are depicted in Fig. 1. For example, 1.2 as the value of an objective means $20 \%$ increase in the value of that objective. This will apply to Fig .2 and Fig. 3-a-Fig. 3-d as well.

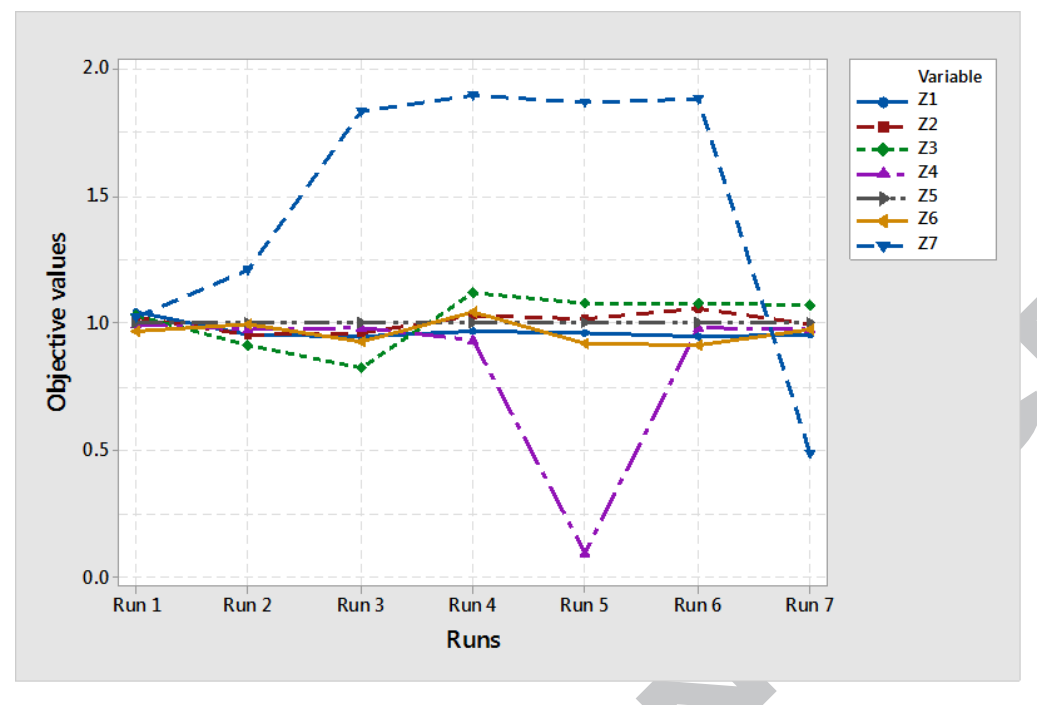

Fig. 1: Pay-off with regard to scenario 1

\subsection{Scenario 2: consider minimisation/maximisation objectives separately}

Consider the maximisation objectives, $Z_{1}$ and $Z_{5}$, and minimisation objectives, $Z_{2}, Z_{3}, Z_{4}, Z_{6}$ and $Z_{7}$, together each time and run the model. The results are presented in Table 8.

Table 8: The outcome of scenario 2

\begin{tabular}{|c|c|c|c|c|c|c|c|}
\cline { 2 - 8 } \multicolumn{1}{c|}{} & $Z_{1}$ & $Z_{2}$ & $Z_{3}$ & $Z_{4}$ & $Z_{5}$ & $Z_{6}$ & $Z_{7}$ \\
\hline Run 1 & 12248948.63 & - & - & - & 0.984265 & - & - \\
\hline Run 2 & & 8106467.071 & 5667.46 & 29381.39 & - & 319662.95 & 0.036432214 \\
\hline
\end{tabular}

\subsection{Scenario 3: conduct trade-off analysis}

Conduct trade-off analysis on the basis of objective values for the average demand scenario, which were presented in Table 5, with respect to conditions that are stated in Table 9. The signs + or before the percentages show the corresponding increase or decrease in objective values. By this scenario, the amount(s) that the given objective(s) need(s) to be sacrificed to improve specific objective(s) is/are determined. The trade-off analysis results have been presented in Table 10 and Fig. 2. 


\begin{tabular}{|c|c|c|c|c|c|}
\hline Run 1 & Run 2 & Run 3 & Run 4 & Run 5 & Run 6 \\
\hline$+10 \%$ in $Z_{1}$ & $-10 \%$ in $Z_{2}$ & $+5 \%$ in $Z_{3}$ & $-5 \%$ in $Z_{7}$ & $-5 \%$ in $Z_{6}$ & $-8 \%$ in $Z_{3}$ \\
$-5 \%$ in $Z_{7}$ & $-5 \%$ in $Z_{5}$ & $-10 \%$ in $Z_{1}$ & $-10 \%$ in $Z_{6}$ & $+10 \%$ in $Z_{2}$ & $-5 \%$ in $Z_{5}$ \\
\hline
\end{tabular}

Table 10: Trade-off analysis with regard to the conditions of scenario 3

\begin{tabular}{|c|c|c|c|c|c|c|c|}
\cline { 2 - 8 } \multicolumn{1}{c|}{} & $Z_{1}$ & $Z_{2}$ & $Z_{3}$ & $Z_{4}$ & $Z_{5}$ & $Z_{6}$ & $Z_{7}$ \\
\hline Run 1 & 13125431 & 8791267.525 & 6289.567 & 32921.591 & 0.99338763 & 363893.052 & 0.01497789 \\
\hline Run 2 & 11232743.85 & 7381200.813 & 6020.572 & 27850.096 & 0.9527377 & 354071.929 & 0.1061323 \\
\hline Run 3 & 10738989 & 7222915.0625 & 6171.63 & 28636.936 & 0.9144639 & 356595.412 & 0.093945 \\
\hline Run 4 & 12689786.013 & 8798227.343 & 5832.96 & 32466.189 & 0.9917634 & 306910.08 & 0.01497789 \\
\hline Run 5 & 12860535.938 & 9021467.661 & 5624.229 & 31739.32 & 0.992875 & 323960.64 & 0.0204766 \\
\hline Run 6 & 12520706.597 & 8652489.63 & 5407.524 & 31905.44 & 0.9527377 & 329689.628 & 0.0323209 \\
\hline
\end{tabular}

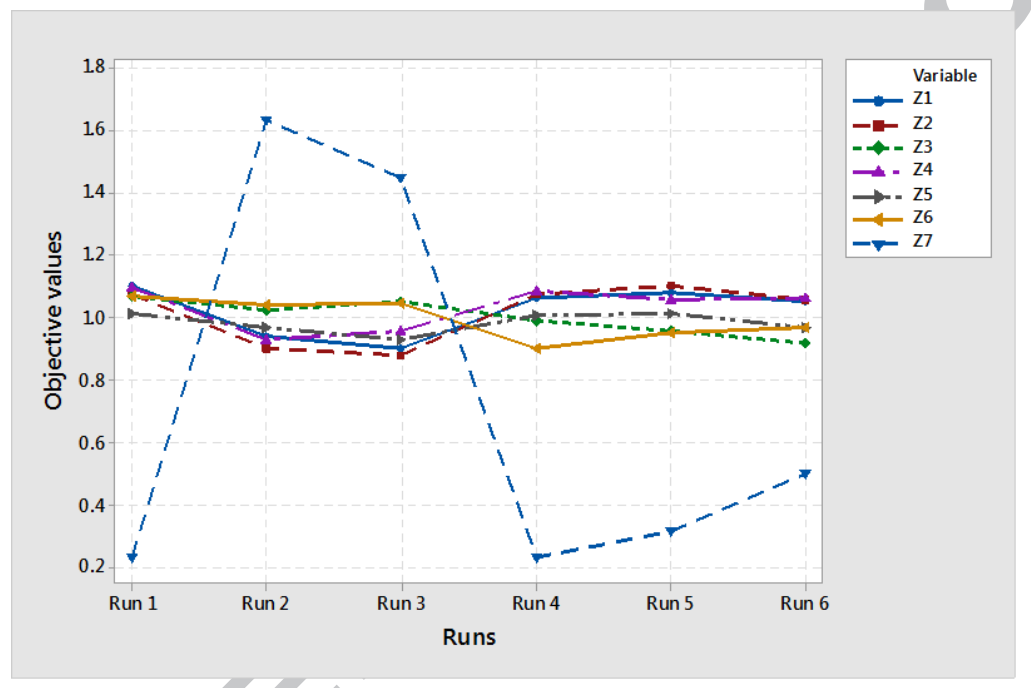

Fig. 2: Trade-off analysis with respect to the conditions of scenario 3

\subsection{Scenario 4: conduct sensitivity analysis}

Analyse the sensitivity of the model to changes in production and subcontracting costs, wage costs and hiring and lay off costs. The implementation data is provided in Table 11. The relevant parameter values are modified on an interval of $30 \%$ decreases to $30 \%$ increases in order to study the resulting effects on the related parts of the model.

Table 11: The implementation data of scenario 4

\begin{tabular}{|l|c|c|c|c|c|c|c|}
\cline { 2 - 8 } \multicolumn{1}{c|}{} & Item & Run 1 & Run 2 & Run 3 & Run 4 & Run 5 & Run 6 \\
\hline Round 1 & $C_{p n}^{t}$ & $-30 \%$ & $-20 \%$ & $-10 \%$ & $10 \%$ & $20 \%$ & $30 \%$ \\
\hline Round 2 & $C_{s n}^{t}$ & $-30 \%$ & $-20 \%$ & $-10 \%$ & $10 \%$ & $20 \%$ & $30 \%$ \\
\hline Round 3 & $C_{r w n}^{t}$ and $C_{\text {ewn }}^{t}$ & $-30 \%$ & $-20 \%$ & $-10 \%$ & $10 \%$ & $20 \%$ & $30 \%$ \\
\hline Round 4 & $\begin{array}{c}C_{r h}^{t}, C_{e h}^{t}, \\
C_{r l}^{t} \text { and } C_{e l}^{t}\end{array}$ & $-30 \%$ & $-20 \%$ & $-10 \%$ & $10 \%$ & $20 \%$ & $30 \%$ \\
\hline
\end{tabular}


Table 12 indicates the amounts of changes for all seven objectives with respect to changes in relevant coefficients. In each round, the objective values which are directly affected by the modifications in the given parameters are bolded.

Table 12: Sensitivity analysis with regard to scenario 4

\begin{tabular}{|c|c|c|c|c|c|c|c|}
\hline & Objectives & Run 1 & Run 2 & Run 3 & Run 4 & Run 5 & Run 6 \\
\hline \multirow{7}{*}{ Round 1} & $Z_{1}$ & 11978977.7 & 11777170.1 & 1175961.5 & 12094228.6 & 11890390.3 & 11993319.1 \\
\hline & $Z_{2}$ & 6127763.775 & 6779257.59 & 7433788.88 & 8917430.85 & 9557748.92 & 10374096.8 \\
\hline & $Z_{3}$ & 5909.88 & 5585.55 & 5961.17 & 6177.673 & 5883.13 & 5919.53 \\
\hline & $Z_{4}$ & 29574.81 & 29546.98 & 29397.9 & 28999.25 & 29178.99 & 29502.16 \\
\hline & $Z_{5}$ & 0.9820683 & 0.9838229 & 0.983443 & 0.9833418 & 0.983048 & 0.98263780 \\
\hline & $Z_{6}$ & 346162.31 & 333689.69 & 336293.26 & 337249.46 & 340409.471 & 345779.13 \\
\hline & $Z_{7}$ & 0.0870636 & 0.0689330 & 0.05222536 & 0.05611806 & 0.06736631 & 0.07540528 \\
\hline \multirow{7}{*}{ Round 2} & $Z_{1}$ & 11970948.6 & 11888339.5 & 11938687.2 & 11970947.8 & 11994482.6 & 12043244.6 \\
\hline & $Z_{2}$ & 7810835.503 & 7942253.08 & 8073017.26 & 8294991.98 & 8455971.04 & 8567514.28 \\
\hline & $Z_{3}$ & 5936.35 & 5878.16 & 5919.53 & 5936.35 & 5875.96 & 5915.94 \\
\hline & $Z_{4}$ & 29384.6 & 29713.52 & 29860.24 & 29384.69 & 29339.40 & 29866.37 \\
\hline & $Z_{5}$ & 0.982965 & 0.9825126 & 0.9835545 & 0.982965 & 0.9826244 & 0.9825690 \\
\hline & $Z_{6}$ & 337189.42 & 337007.85 & 332336.63 & 348344.63 & 340137.1 & 344612.07 \\
\hline & $Z_{7}$ & 0.07054377 & 0.07335075 & 0.07065272 & 0.07054377 & 0.05440478 & 0.06644299 \\
\hline \multirow{7}{*}{ Round 3} & $Z_{1}$ & 11888453.21 & 11819944.1 & 11819947.6 & 11931728.9 & 12055708.2 & 11820480 \\
\hline & $Z_{2}$ & 8127843.28 & 8168442.04 & 8174956.05 & 8221162.56 & 8247022.72 & 8274934.62 \\
\hline & $Z_{3}$ & 4312.78 & 4652.56 & 5233.92 & 6233.93 & 7070.12 & 7785.24 \\
\hline & $Z_{4}$ & 38173.91 & 38882.99 & 38882.99 & 38187.12 & 38783.45 & 38349.89 \\
\hline & $Z_{5}$ & 0.9836345 & 0.983975 & 0.98397541 & 0.9827611 & 0.98279043 & 0.9832633 \\
\hline & $Z_{6}$ & 331769.97 & 330544.33 & 330544.33 & 339166.26 & 333404 & 337189.42 \\
\hline & $Z_{7}$ & 0.07078570 & 0.07176568 & 0.07176568 & 0.07351944 & 0.07160418 & 0.05478359 \\
\hline \multirow{7}{*}{ Round 4} & $Z_{1}$ & 12030562.3 & 12030562.3 & 12160328.4 & 11960899.4 & 12068253.1 & 11914736.3 \\
\hline & $Z_{2}$ & 82206919.24 & 8206919.24 & 8238423.27 & 8157009.02 & 8200127.49 & 8171065.31 \\
\hline & $Z_{3}$ & 5981.86 & 5981.86 & 5901.60 & 5636.85 & 5676.84 & 5776.95 \\
\hline & $Z_{4}$ & 20635.48 & 23583.41 & 26795.11 & 23426.65 & 35680.85 & 38929.80 \\
\hline & $Z_{5}$ & 0.9826999 & 0.9827001 & 0.9827545 & 0.9834611 & 0.9825451 & 0.9831793 \\
\hline & $Z_{6}$ & 347517.29 & 347517.87 & 350388.53 & 334401.2 & 337884.39 & 339201.40 \\
\hline & $Z_{7}$ & 0.06139187 & 0.06139187 & 0.06751612 & 0.0648144 & 0.0530523 & 0.0783841 \\
\hline
\end{tabular}

The results of the sensitivity analysis in regard to scenario 4 have also been presented in Fig. 3-a-Fig. 3-d. 

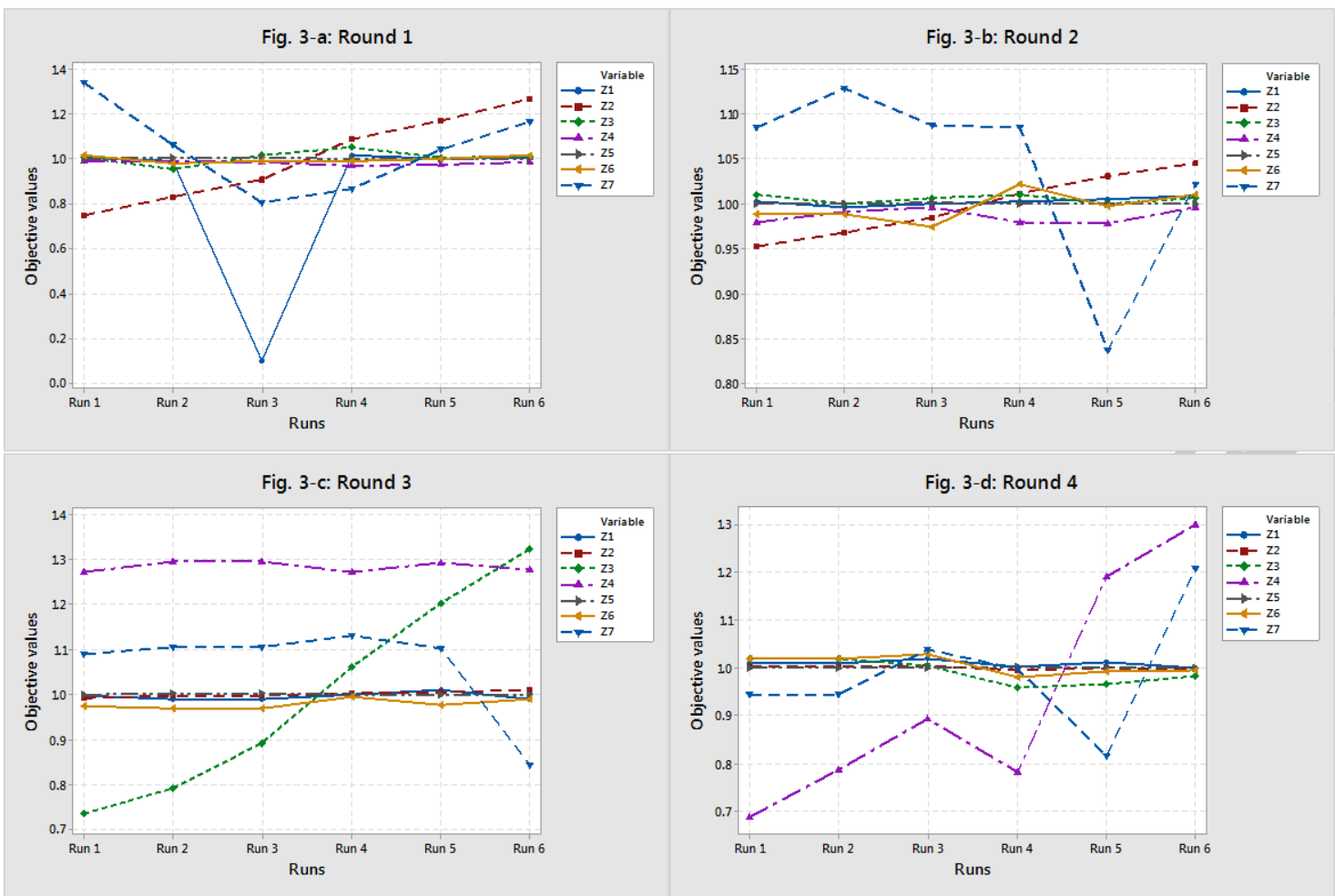

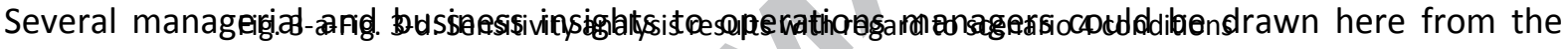
abovementioned scenarios:

- It can be seen from Table 7 and Table 8 that there exist trade-offs between objectives. For instance, in scenario 1 when the model is solved for a single objective in each run, each objective reaches its most optimum value as there is no need to sacrifice an objective in favour of other objectives.

- Compared to the objective values presented in Table 5, for the situation that the whole set of objective functions are considered simultaneously in the solution process, the quantities of objectives obtained with regard to the conditions of scenario 2 are more satisfactory. Apart from the smaller number of objectives, 2 for run 1 and 5 for run 2 compared to the 7 as the total number of objectives, this would probably be due to the homogeneity of the nature of the objective functions as well. That is, they are all of maximisation or minimisation type which may have reduced the inconsistency between the objectives.

- According to trade-off analysis in Table 10 and Fig. 2, to decision makers, i.e. the company managers, the objectives $Z_{1}$ and $Z_{2}$ have the highest importance. That is, they prefer to sacrifice less from $Z_{1}$ and $Z_{2}$ to get more from other objectives. They value $Z_{6}$ most in the next level of importance. 
- As is evident from Table 12, the developed APP model is most sensitive to changes in production costs $C_{p n}^{t}$, since the total production costs shows the biggest relative changes from each run to another run accordingly.

- Changes in subcontracting cost are also expected to have an impact on total production costs with similar intensity compared to that of production costs. Due to the relatively small quantity of the subcontracted orders, however, the magnitude of the respective fluctuations in total production costs, as result of increase/decrease in subcontracting costs, turns out to be much lower.

- Variations in wage rates paid to workers in both regular shift and extra shift, $C_{r w n}^{t}$ and $C_{e w n}^{t}$, correspondingly affect $Z_{2}$ and $Z_{3}$, i.e. total production costs and total labour productivity costs. Although the values of the objective functions are chosen among a set of Paretooptimal solutions by the decision makers during several classifications, a proportionate increase or decrease in their quantities are observed in response to increase/decrease in wage rates.

A similar trend is seen for round 4 where fluctuations in costs of changes in workforce level occur in accordance with variations in hiring and lay off costs, which have been provided in detail in Table 12.

\section{Conclusions and future research directions}

This study proposed a novel stochastic, nonlinear, multi-stage, multi-objective decision making model to APP based on mixed chase and level strategy which considers multiple objectives such as total revenue, total production costs, total labour productivity costs, total costs of the changes in workforce level, customer services, etc. subject to constraints on inventories, backorders, subcontracting, workforce level, and so forth where the forecasted demand acts as the main source of uncertainty.

The recourse approach of stochastic programming led to infeasible space due to the large number of highly inconsistent constraints related to different demand scenarios. The wait and see method, as another stochastic programming approach, was used instead.

The constructed stochastic, nonlinear, nonconvex, non-differentiable, multi-objective optimisation model for the APP problem was solved using WWW-NIMBUS software. The solution determined the optimal values of the production in regular shift and extra shift, backorder, inventory, 
subcontracting, workforce hired and laid off in regular shift and extra shift, product price, etc. over the planning horizon for the company under study in presence of uncertainty.

Further experiments with the model were performed by sensitivity analysis via changing different parameters of the model, and by different forms of trade-off analysis.

However, similar to every research work, this study also has some limitations as follows.

In this study, we assumed that the demand volume scenarios will be the same in all consecutive time periods. That is, if, for example, demand quantity is high in first time period, it will also be high in all future time periods. We made this assumption based on our discussion with the company's managers, where according to their long term experience with customer demand in the company under study, they approved that demand normally has similar mood in several consecutive time periods while maintaining the seasonality pattern. However, this assumption could be invalid in different cases and needs to be taken into account in relevant APP models.

The proposed model in present research was validated by implementing it in an industrial case which is both capital-intensive and labour-intensive. Implementing the model using data from more labour-intensive industries especially regarding the frequent hiring and lay off and resulting productivity issues that are more relevant in chase strategies, could provide more insights.

Several future research directions are recommended for APP, especially by utilising the management science techniques:

i. Recourse approach as one of major stochastic programming approaches has a serious drawback. The main shortcoming of this approach is that it considers all constraints relating to different scenarios with equal probability (with certainty or $P=1$, where $P$ stands for the probability of associated scenarios) in constraints section of the stochastic mathematical programming. In other words, it puts all the constraints relating to different scenarios together, and solves the problem where the objective function is the expected value regarding different scenarios. This does not sound true, since when all constraints relating to different scenarios are put together in one mathematical programming problem, it looks like all scenarios happen at the same time with equal probabilities (with $\mathrm{P}=1$ or certainty). $\mathrm{A}$ suitable methodology needs to be developed to resolve this shortcoming.

ii. APP problems modelled by multi-stage stochastic programming techniques, e.g. Markov decision process would normally need to deal with the curse of dimensionality due to rather large scale of real world APP decision problems. One of the efficient methods to handle this 
issue can be Monte Carlo methods employed within the reinforcement learning structure to find the optimal actions in each stage by maximising the reward (profit).

iii. Aggregate production planners have traditionally been doing APP for the sake of maximising profit without properly taking into account the sustainability aspects, e.g. workers mental and physical health regarding workloads as the result of operating in overtime and multiple shifts, increased workplace incidents/injuries due to excessive overtime and nightshifts, negative psychological effects of frequent hiring and lay off on employees, greenhouse gas emissions, declined customer satisfaction level because of regular backordering, and so forth. Very little research has been conducted on APP with regard to sustainability factors. Therefore, these sustainability dimensions need to be systematically incorporated into analytical models of APP, e.g. simulation models, mathematical models, etc. in order to develop a decision making framework which is more consistent with contemporary operations management requirements.

iv. The outlook for Big Data driven approaches to APP particularly in larger manufacturing corporations, e.g. big car producing companies, airplane manufacturing corporations, etc. in order to provide decision support systems which have specific utilities in production planning and control activities, would be a promising area of research.

\section{Appendix}

Table 2: Unadjusted forecasted product demand (in bottles)

\begin{tabular}{|c|c|c|c|c|c|}
\cline { 3 - 6 } \multicolumn{2}{c|}{} & \multicolumn{4}{c|}{ Time period } \\
\hline \multirow{3}{*}{ Product } & Scenario & 1 & 2 & 3 & 4 \\
\hline \multirow{3}{*}{1} & L & 9747943 & 11123480 & 8120967 & 6065191 \\
\hline \multirow{3}{*}{2} & A & 14982840 & 20343160 & 16926800 & 11414810 \\
\cline { 2 - 6 } & H & 15296181 & 18803319 & 12973106 & 9525384 \\
\cline { 2 - 6 } & L & 5021774 & 6134489 & 4343471 & 3264113 \\
\cline { 2 - 6 } & A & 7812561 & 10169900 & 8920985 & 5967746 \\
\hline \multirow{3}{*}{3} & H & 7674811 & 8310541 & 6449115 & 5029168 \\
\cline { 2 - 6 } & L & 1561509 & 1909242 & 1354043 & 1021289 \\
\cline { 2 - 6 } & A & 2452971 & 3271535 & 2770720 & 1836216 \\
\cline { 2 - 6 } & H & 2388680 & 2915203 & 2038001 & 1512800 \\
\hline
\end{tabular}

Table 3: Cost figures (in GBP)

\begin{tabular}{|c|c|c|c|c|c|c|c|}
\hline Product & Time period & $C_{p n}^{t}$ & $C_{r w n}^{t}$ & $C_{\text {ewn }}^{t}$ & $C_{s n}^{t}$ & $C_{b n}^{t}$ & $C_{i n}^{t}$ \\
\hline \multirow{3}{*}{1} & 1 & 0.0638 & 0.8654 & 0.9952 & 0.0721 & 0.0731 & 0.000715 \\
\cline { 2 - 8 } & 2 & 0.0650 & 0.8654 & 0.9952 & 0.0735 & 0.0745 & 0.000875 \\
\cline { 2 - 8 } & 3 & 0.0663 & 0.8654 & 0.9952 & 0.0750 & 0.0760 & 0.000595 \\
\hline
\end{tabular}




\begin{tabular}{|c|c|c|c|c|c|c|c|}
\hline & 4 & 0.0677 & 0.8654 & 0.9952 & 0.0765 & 0.0775 & 0.000455 \\
\hline \multirow{3}{*}{2} & 1 & 0.0638 & 0.8654 & 0.9952 & 0.0721 & 0.0731 & 0.000715 \\
\cline { 2 - 8 } & 2 & 0.0650 & 0.8654 & 0.9952 & 0.0735 & 0.0745 & 0.000875 \\
\cline { 2 - 8 } & 3 & 0.0663 & 0.8654 & 0.9952 & 0.0750 & 0.0760 & 0.000595 \\
\cline { 2 - 8 } & 4 & 0.0677 & 0.8654 & 0.9952 & 0.0765 & 0.0775 & 0.000455 \\
\cline { 2 - 8 } 3 & 1 & 0.0638 & 0.8654 & 0.9952 & 0.0721 & 0.0731 & 0.000715 \\
\cline { 2 - 8 } & 2 & 0.0650 & 0.8654 & 0.9952 & 0.0735 & 0.0745 & 0.000875 \\
\cline { 2 - 9 } & 3 & 0.0663 & 0.8654 & 0.9952 & 0.0750 & 0.0760 & 0.000595 \\
\cline { 2 - 9 } & 4 & 0.0677 & 0.8654 & 0.9952 & 0.0765 & 0.0775 & 0.000455 \\
\hline
\end{tabular}

Table 3: (Continued)

\begin{tabular}{|c|c|c|c|c|}
\hline Time period & $C_{r h}^{t}$ & $C_{r l}^{t}$ & $C_{e h}^{t}$ & 3 \\
1 \\
\hline 1 & 3 & 1 & 3.06 & 1.02 \\
\hline 2 & 3.06 & 1.02 & 3.121 & 1.040 \\
\hline 4 & 3.121 & 1.040 & 3.183 & 1.061 \\
\hline
\end{tabular}

Table 4: The input data

\begin{tabular}{|c|c|c|c|c|}
\hline Product & Time period & $S_{n s}^{t}$ & $B_{n s \max }^{t}$ & $A C_{n s \max }^{t}$ \\
\hline \multirow{4}{*}{1} & 1 & 3024836 & 1814902 & 33315 \\
\hline & 2 & 3582189 & 2209314 & 33315 \\
\hline & 3 & 3540994 & 1524597 & 33315 \\
\hline & 4 & 2057449 & 1234470 & 33315 \\
\hline \multirow{4}{*}{2} & 1 & 1576850 & 946110 & 16658 \\
\hline & 2 & 1728888 & 1097333 & 16658 \\
\hline & 3 & 1767473 & 820484 & 16658 \\
\hline & 4 & 1051584 & 630950 & 16658 \\
\hline \multirow{4}{*}{3} & 1 & 490177 & 294106 & 5553 \\
\hline & 2 & 1687784 & 352670 & 5553 \\
\hline & 3 & 622476 & 254861 & 5553 \\
\hline & 4 & 324150 & 194490 & 5553 \\
\hline
\end{tabular}

Table 4: (Continued)

\begin{tabular}{|c|c|c|c|c|c|}
\cline { 3 - 5 } \multicolumn{2}{c|}{} & \multicolumn{4}{c|}{$F P R_{n s}^{t}$} \\
\cline { 2 - 6 } \multicolumn{2}{c|}{} & \multicolumn{4}{c|}{ Time period } \\
\hline \multirow{3}{*}{ Product } & Scenario & 1 & 2 & 3 & 4 \\
\hline \multirow{3}{*}{1} & $\mathrm{~L}$ & 0.1044 & 0.1078 & 0.1163 & 0.1080 \\
\cline { 2 - 6 } & $\mathrm{A}$ & 0.1044 & 0.1078 & 0.1163 & 0.1080 \\
\cline { 2 - 6 } & $\mathrm{H}$ & 0.0847 & 0.1010 & 0.1420 & 0.1017 \\
\hline \multirow{3}{*}{2} & $\mathrm{~L}$ & 0.1052 & 0.1091 & 0.1166 & 0.1098 \\
\cline { 2 - 6 } & $\mathrm{A}$ & 0.1052 & 0.1091 & 0.1166 & 0.1098 \\
\cline { 2 - 6 } & $\mathrm{H}$ & 0.0858 & 0.1029 & 0.1365 & 0.1064 \\
\hline \multirow{3}{*}{3} & $\mathrm{~L}$ & 0.1058 & 0.1097 & 0.1180 & 0.1105 \\
\cline { 2 - 6 } & $\mathrm{A}$ & 0.1058 & 0.1097 & 0.1180 & 0.1105 \\
\cline { 2 - 6 } & $\mathrm{H}$ & 0.0909 & 0.1053 & 0.1359 & 0.1080 \\
\hline
\end{tabular}


Table 4: (Continued)

\begin{tabular}{|c|c|c|c|c|c|}
\cline { 3 - 5 } \multicolumn{2}{c|}{} & \multicolumn{4}{c|}{ TAC } \\
\cline { 2 - 6 } \multicolumn{2}{c|}{} & \multicolumn{4}{c|}{} \\
\hline \multirow{3}{*}{ Product } & Scenario & 1 & 2 & 3 & 4 \\
\hline \multirow{3}{*}{1} & L & - & 14441 & 8756 & 14330 \\
\cline { 2 - 6 } & A & - & 14441 & 8756 & 14330 \\
\cline { 2 - 6 } & H & 16219 & 13910 & 10604 & 13827 \\
\hline \multirow{3}{*}{2} & L & - & 7127 & 4579 & 6840 \\
\cline { 2 - 6 } & A & - & 7127 & 4579 & 6840 \\
\hline \multirow{3}{*}{3} & H & 8145 & 6891 & 5445 & 6692 \\
\cline { 2 - 6 } & L & - & 2448 & 1547 & 2358 \\
\cline { 2 - 6 } & A & - & 2448 & 1547 & 2358 \\
\hline
\end{tabular}

Table 4: Continued

\begin{tabular}{|c|c|c|c|c|}
\cline { 2 - 5 } \multicolumn{1}{c|}{} & \multicolumn{4}{c|}{$B_{n \delta}^{t}$} \\
\cline { 2 - 5 } \multicolumn{1}{c|}{} & \multicolumn{4}{c|}{ Time period } \\
\hline Product & 1 & 2 & 3 & 4 \\
\hline 1 & 907451 & 1325588 & 414758 & 378570 \\
\hline 2 & 473055 & 658400 & 492290 & 116694 \\
\hline 3 & 147053 & 211602 & 152917 & \multicolumn{2}{c}{} \\
\hline
\end{tabular}

\section{References}

Buxey, G. (1995). A managerial perspective on aggregate planning. International Journal of Production Economics, 41 (1-3), 127-133.

Buxey, G. (2003). Strategy not tactics drives aggregate planning. International Journal of Production Economics, 85(3), 331-346.

Buxey, G. (2005). Aggregate planning for seasonal demand: reconciling theory with practice. International Journal of Operations and Production Management, 25 (11), 1083-1100.

Chen, Y.K., \& Liao, H.C. (2003). An investigation on selection of simplified aggregate production planning strategies using MADM approaches. International Journal of Production Research, 41(14), 3359-3374.

Entezaminia, A., Heidari, M., \& Rahmani, D. (2016). Robust aggregate production planning in a green supply chain under uncertainty considering reverse logistics: a case study. The International Journal of Advanced Manufacturing Technology, DOI: 10.1007/s00170-016-9459-6.

Günther, H.O. (1982). A comparison of two classes of aggregate production planning models under stochastic demand. Engineering Costs and Production Economics, 6(1), 89-97.

Heizer, J., \& Render, B. (2001). Production and operations management: strategic and tactical decisions. Upper Saddle River, NJ: Prentice Hall.

Huselin, M.A. (1998). The impact of human resource management practices on turnover, productivity, and corporate financial performance. In C. Mabey, G. Salaman, \& J. Storey (Eds.), Strategic human resource management: a reader (pp. 104-127). London: Sage.

Jamalnia, A., \& Feili, A. (2013). A simulation testing and analysis of aggregate production planning strategies. Production Planning \& Control, 24(6), 423-448.

Kanyalkar, A.P., \& Adil, G.K. (2010). A robust optimisation model for aggregate and detailed planning of a multi-site procurement-production-distribution system. International Journal of Production Research, 48(3), 635-656. 
Kher, H.V., Malhotra, M.K., Philipoom, P.R., \& Fry, T.D. (1999). Modelling simultaneous worker learning and forgetting in dual recourse constrained systems. European Journal of Operational Research, 115(1), 158-172.

Kleindorfer, P., \& Kunreuther, H. (1978). Stochastic Horizons for the Aggregate Planning Problem. Management Science, 24(5), 485-497.

Leung, S.C.H., \& Wu, Y. (2004). A robust optimization model for stochastic aggregate production planning. Production Planning \& Control, 15(5), 502-514.

Leung, S.C.H., Wu, Y., \& Lai, K.K. (2006). A stochastic programming approach for multi-site aggregate production planning. Journal of the Operational Research Society, 57(2), 123-132.

Li, G., \& Rajagopalan, S. (1998). A learning curve model with knowledge depreciation. European Journal of Operational Research, 105(1), 143-154.

Lieckens, K., \& Vandaele, N. (2014). A decision support system for the stochastic aggregate planning problem. http://ssrn.com/abstract=2419376/16/03/20.

Lockett, A.G., \& Muhlemann, A.P. (1978). A stochastic programming model for aggregate production planning. European Journal of Operational Research, 2(5), 350-356.

Makui, A., Heydari, M., Aazami, A., \& Dehghani, E. (2016). Accelerating Benders decomposition approach for robust aggregate production planning of products with a very limited expiration date. Computers \& Industrial Engineering, 100 (2016), 34-51.

Miettinen, K., \& Mäkelä, M.M. (2006). Synchronous Approach in Interactive Multi-objective Optimization. European Journal of Operational Research, 170(3), 909-922.

Mirzapour Al-e-hashem, S.M.J., Malekly, H., \& Aryanezhad, M.B. (2011). A multi-objective robust optimization model for multi-product multi-site aggregate production planning in a supply chain under uncertainty. International Journal of Production Economics, 134(1), 28-42.

Mirzapour Al-e-hashem, S.M.J., Aryanezhad, M.B., \& Sadjadi, S.J. (2012). An efficient algorithm to solve a multi-objective robust aggregate production planning in an uncertain environment. The International Journal of Advanced Manufacturing Technology, 58(5), 765-782.

Mirzapour Al-e-hashem, S.M.J., Baboli, A., \& Sazvar, Z. (2013). A stochastic aggregate production planning model in a green supply chain: Considering flexible lead times, nonlinear purchase and shortage cost functions. European Journal of Operational Research, 230(1), 26-41.

Modarres, M., \& Izadpanahi, E. (2016). Aggregate production planning by focusing on energy saving: A robust optimization approach. Journal of Cleaner Production, 133 (2016), 1074-1085.

Niknamfar, A.H., Akhavan Niaki, S.T., \& Pasandideh, S.H.R. (2015). Robust optimization approach for an aggregate production-distribution planning in a three-level supply chain. The International Journal of Advanced Manufacturing Technology, 76(1), 623-634.

Ning, Y., Liu, J., \& Yan, L. (2013). Uncertain aggregate production planning. Soft Computing, 17(4), 617-624.

Nowak, M. (2013). An interactive procedure for aggregate production planning. Croatian Operational Research Review, 4(1), 247-57.

Piper, C.J., \& Vachon, S. (2001). Accounting for productivity losses in aggregate planning. International Journal of Production Research, 39 (17), 4001-4012.

Rakes, T.R., Franz, L.S., \& Wynne, A.J. (1984). Aggregate production planning using chanceconstrained goal programming. International Journal of Production Research, 22(4), 673-684.

Reid, R.D., \& Sanders., N.R. (2002). Operations management. New York: John Wiley and Sons.

Schroeder, R.G. (2003). Operations management, contemporary concepts and cases. New York: McGraw-Hill.

Slack, N., Brandon-Jones, A., \& Johnston, R. (2013). Operations management. Harlow: Pearson Education Limited. 
Thomas, L.J., \& McClain, J.O. (1993). An overview of production planning. In S.G. Grave, A.H.G. Rinnooy Kan, \& P.H. Zipkin (Eds.), Logistics of production and inventory (pp. 333-370). Amsterdam: North-Holland.

Thompson, S.D., Wantanabe, D.T., \& Davis, W.J. (1993). A comparative study of aggregate production planning strategies under conditions of uncertainty and cyclic product demands. International Journal of Production Research, 31(8), 1957-1979.

Vörös, J. (1999). On the risk-based aggregate planning for seasonal products. International Journal of Production Economics, 59(1-3), 195-201. 


\section{Highlights}

- A decision model is proposed to aggregate production planning under uncertainty.

- The proposed multiple objective model is based on mixed chase and level strategy.

- The model is validated using real world data from beverage manufacturing industry.

- The wait and see approach is applied to solve the constructed decision model.

- Sensitivity analysis and several forms of trade-off analysis are also conducted. 